Review

\title{
Layered Growth and Crystallization in Calcareous Biominerals: Impact of Structural and Chemical Evidence on Two Major Concepts in Invertebrate Biomineralization Studies
}

\author{
Jean-Pierre Cuif $^{1{ }^{* *},}$, Yannicke Dauphin ${ }^{1}$, Gernot Nehrke ${ }^{2}$, Julius Nouet ${ }^{1}$ and
}

Alberto Perez-Huerta ${ }^{3}$

1 Geological laboratory IDES, Bat. 504, Faculty of Science, 91405 ORSAY, France; E-Mails: yannicke.dauphin@u-psud.fr(Y.D.); julius.nouet@u-psud.fr(J.N.)

2 Alfred Wegener Institute for Polar and Marine Research, Am Handelshafen 12, Bremerhaven 27570, Germany; E-Mail: gernot.nehrke@awi.de

3 Department of Geological Sciences, The University of Alabama, 2018 Bevill Building, Tuscaloosa, AL 35487, USA; E-Mail: aphuerta@as.ua.edu

* Author to whom correspondence should be addressed; E-Mail: jean-pierre.cuif@u-psud.fr; Tel.: +33-1-69-15-67-41; Fax: +33-1-69-15-61-21.

Received: 16 January 2012; in revised form: 2 February 2012 / Accepted: 13 February 2012 / Published: 27 February 2012

\begin{abstract}
In several recent models of invertebrate skeletogenesis, Ca-carbonate crystallization occurs within a liquid-filled chamber. No explanation is given neither for the simultaneous occurrence of distinct polymorphs of Ca-carbonate within these liquid volumes, nor for the spatial arrangement of the mineral units which are always organized in species-specific structural sequences. Results of a series of physical characterizations applied to reference skeletal materials reveal the inadequacy of this liquid-filled chamber model to account for structural and chemical properties of the shell building units. Simultaneously, these data provide convergent pieces of evidence for a specific mode of crystallization developed throughout various invertebrate phyla, supporting the hypothesized "common strategy" based on a multi-scaled control exerted on formation of their calcareous hard parts.
\end{abstract}

Keywords: biocrystallization; layered growth-mode; reticulate pattern 


\section{Introduction}

Since early observations of mollusk shell structures [1,2], a continuous series of investigations has unambiguously established the common character of the calcareous skeletons built by numerous organisms (mainly Invertebrates). Independent of their sizes, shapes and functions (protection, supporting frameworks, etc.), growth of these calcareous skeletons relies on the formation of three-dimensionally arranged units whose crystalline appearance is easily visible under polarizing microscope. Thin sections of crystals and rocks - practical innovations introduced by Nicol in 1815 and Sorby in 1849 respectively — coupled to polarized light examination at the microscope, initiated by Fox-Talbot in 1834, were developed during 19th century, leading to some remarkable monographs that emphasized the strict control exerted by the living systems on their skeletal components. Some milestone treatises [3-5], as well as specific studies such as taxonomic investigations carried out by Ogilvie on Scleractinia corallites [6,7], demonstrated the general value of the concept of skeletal microstructure as the taxonomically dependent spatial arrangement of the crystalline calcareous units produced by living systems.

Regarding either the place where such a controlled crystallization occurs or the methods by which this control is exerted, the current working framework relies on a few simple concepts, among which the most widely shared is undoubtedly the formation of calcium carbonate crystals within an extra-epithelial liquid chamber. Recent literature offers many representations of such liquid-filled crystallization spaces, located between the mineralizing epithelium (external layer of the mantle of mollusks or basal ectoderm of the coral polyps) and the growing surface of the calcareous structure. For instance in corals, Furla et al. [8] or Adkins et al. [9] provided such schemes and equivalent models for mollusks were presented by Petit [10], Saleuddin and Petit [11], Volkmer [12], Jacob et al. [13] and Dove [14].

This liquid volume is named extra-pallial fluid in mollusks or sub-ectodermal fluid in corals, but in both cases locations and functions are essentially identical. Within this liquid volume a biological mechanism is in charge of creating conditions for ionic saturation allowing crystallization of calcium carbonate to occur. Whatever the diversity of ion routes still in discussion (intracellular with dedicated ion pumps, paracellular i.e., between membranes of adjacent cells (see [15] for review), or sometimes directly provided by sea water "leaks" [9]), crystallization admittedly relies on the assemblage of the calcium and carbonate ions following the thermodynamic rules of mineral physical chemistry for mineral formation.

Of course, it has long been obvious that sizes and shapes of the mineral components that create invertebrate skeletons never correspond to those of calcareous crystals grown in saturated solutions; therefore an additional mechanism is required to account for the recognized diversity and taxonomic specificity of the skeleton microstructural units. As a second working concept in the biocrystallization research area, it is widely admitted that the shaping mechanism leading to the taxonomy dependent morphologies of the microstructural units involves clusters of organic molecules whose interaction with surfaces of the growing crystals modifies the normal growth rate for each crystallographic axis. Therefore deciphering biochemical compositions of the organic components playing such key roles in the formation of the microstructural units is a long standing research question, resulting in molecular models of organic architectures acting as crystallization triggers and drivers [16,17]. 
Since the pioneering in vitro investigations by Kitano and Hood [18] until the high resolution approaches from De Yoreo and Dove using atomic force microscopy [19], numerous and variously designed experiments have shown and quantified forces involved in these interactions between the lattice of calcium carbonate crystals (most commonly calcite) and the organic molecules present in solutions where crystals are immersed. In the attempt to reproduce the organo-mineral interactions leading to the formation of biocrystals - the essence of the "biomimetic" approach — many of the experimental studies were carried out using organic components extracted from mollusk shells, coral skeletons, etc.

Although regularly increasing [20], the number of biochemical compounds identified to be involved in the mineralization process has remained rather low until recent years. Applying a genomic approach to cells of the mineralizing tissues has revealed a new scale in complexity for these molecular assemblages. It is now certain that several tens or hundreds of molecules are produced by the mineralizing epithelia, potentially (but not necessarily) involved in the biomineralization processes. Even more importantly, an unexpectedly high diversity was discovered at the phylum level, between compositions of the mineralizing phases of the calcifying organisms, casting doubt on the existence of a common biochemical framework valid for calcification in the different phyla. This led Wilt et al. $[21,22]$ to suggest, regarding the used method for controlling crystallization of their skeletal hard parts, that phyla might have in common only "basic strategies".

Surprisingly, information about a possible common method used by living organisms to control the formation of their calcareous hard parts is the main emerging result of a reverse approach of biominerals developed during the three last decades. In parallel to molecular investigations aiming at creating models of organic compounds potentially active in formation of the growing crystals, a top-down structural approach of calcareous biomaterials was carried out, studying the skeletal units with progressively increased spatial resolutions. Basically, the hypothesis was made that between molecular architectures (sub-nanometer length-scales) and the shell microstructures described in the above cited treatises (dimensionally in the ten to hundred micrometer ranges), intermediate levels of control may exist to ensure the coordinated development of the calcareous building units during shell growth. It was expected that the development of preparative methods focusing on the spatial distributions of organic and mineral phases would reveal structural or chemical traces providing information about the day-to-day activity of the mineralizing organs.

Compared to previous investigators who mainly used optical microscopes and transmission electron microscopes (TEM works by Grégoire and Wada covering more than 25 years illustrate this period), research during the three last decades has been greatly favored by a remarkable development of new physical methods allowing structural observations to be carried out largely below the resolution of classical optical microscopes. Essentially, continuity in structural observations can be maintained through more than three orders of magnitude, from optical microscopy length scales to the nanometer range. Through a series of relatively simple preparative processes (like enzymatic or acido-fixative etchings) the mode of growth of the structural units forming invertebrate shells can now be described with an unprecedented resolution.

These methodological improvements have produced a significant amount of information about the organization of the skeletal units of invertebrate skeletons at the micrometer and sub-micrometer length scales. Some of these results are gathered here in order to exemplify the main consequence of this top-down approach: the remarkable convergence of the methods by which phylogenetically distant 
organisms control their skeletogenesis at the nanometer range. There is a striking contrast between the endless variations in morphologies and spatial arrangements of the skeletal units through invertebrate skeletons and, on the other hand, the similarities that have been revealed regarding the mode of growth of biominerals observed at the micrometer level and the common reticulate crystallization patterns appearing at the nanometer length-scales. The concept of "common strategy" in the control of crystallization, as hypothesized by Wilt et al. [21,22] finds full support in these results. Practically, this is a multi-scaled interplay between organic and mineral components of the shells which is illustrated by the following pictures, revealing how accurate and permanent this control is and providing at the same time multiple physical and chemical evidence contradicting in many respects some currently accepted concepts and crystallization schemes.

\section{Layered Growth of Some Skeleton Building Units Through Structural and Chemical Investigations at the Micrometer Length-Scales}

Surprisingly, the cited models [8-14] illustrating formation of mollusk and coral skeletons are closely similar, although classical views admit a high level difference with respect to control exerted on their respective crystallization processes. Coral skeletons are considered as "biologically induced" structures (i.e., almost uncontrolled), in contrast to mollusk shell built by "matrix mediated" biocrystals, whose full control by specifically secreted organic compounds is accepted [23,24]. Comparison of micrometer-scaled structural and chemical data allows a re-evaluation of this widely shared distinction.

\subsection{Calcite Prisms in Bivalve Mollusks}

As one of the earliest skeletal units ever observed, calcite prisms which build the outer layer of the Pinna shell (Bivalve mollusk) deserve particular interest. Easily visible (with the naked eye or a simple lens) owing to their size and very simple three-dimensional arrangement, their remarkably simple morphological pattern (Figure 1a-e) was already illustrated by Bowerbank on his Figure $8[1,14]$. Crystallographic examination reinforces the concept of the prism as a simple crystal. Under cross-nicol illumination, transverse sections show color homogeneity for each prism (Figure $1 \mathrm{f}-\mathrm{g}$ ), a change in color from prism to prism assessing the slight deviations of their $c$ axis from strict perpendicularity to shell surface. Such a regular spatial disposition makes this type of skeletal unit ideal material for a theoretical approach of biocrystallization (see [25] for review).

Taking advantage of a possible lateral view of the prisms at the external edge of a growth lamella (Figure 1b, arrow), the stratified mode of growth of the prisms is already apparent (Figure 1i). Such a stratified structure of the calcite prisms was illustrated first by Grégoire [26], but owing to the preparative process used, synchronism between mineralization layers of neighbor prisms was not visible. This important growth pattern is obvious, however, on wider sections perpendicular to the shell surface after etching (Figure 2a-c). Although neighbor prisms are separated by strong organic envelopes, synchronism in formation of the superposed elementary mineralized layers of prisms is assessed by correlation between growth lines (Figure 2a, arrows) and by the perfect similitude of their variations in thickness (Figure $2 \mathrm{a}-\mathrm{c}$ ). 
Regarding the surprising continuity of mineral layers through the strong polygonal organic envelopes of the prisms, the question arises of their individual but obviously synchronic development. Actually, growth of these envelopes is also a stepping process, as shown by Figures $1 \mathrm{j}$ and $2 \mathrm{c}-\mathrm{h}$. A one week decay of the honeycomb-like organic mesh in water resulted in partial hydrolysis and separation of the upper growth step of the envelopes (Figure 1j). Sometimes, the stepping growth process of the prism envelopes is clearly visible on the inner side of envelopes (Figure 2d) and even perfectly illustrated by the morphology of envelopes themselves in longitudinal sections (Figure 2e-h).

Figure 1. Layered growth in the prisms of the mollusk pelecypod Pinna: the historical reference for biocrystals. a-e: The building units of the outer layer of the Pinna shell $(\mathbf{a}, \mathbf{b})$ are closely assembled linear polygonal prisms (c,d) with massive aspect of fractures (e); (f,g) Thin sections observed under the microscope between cross-nicols. Owing to the high refractive index of calcite, such primary colors are obtained far below the standard thickness: here about 5-6 micrometers. Note the homogeneity of color for each prism on the transverse section (f). Difference in color from prism to prism, results from variation of orientation of the crystallographic $c$ axis (the elongation axis of the prism). When prisms are sectioned in length, color is more variable because obliquity of the sections with respect to elongation axis creates variations in the thickness with the possibility of superposed contributions of two prisms; (h) Strong acidic etching: the polygonal network of prism envelopes has been made free; (i) Layered growth visible without any preparative process of the lateral side of the mineralized unit. Note also the granular aspect of the growth surface; (j) After a one week decay in water the polygonal network corresponding to a single growth layer has been freed (and slightly displaced) from underlying envelopes.

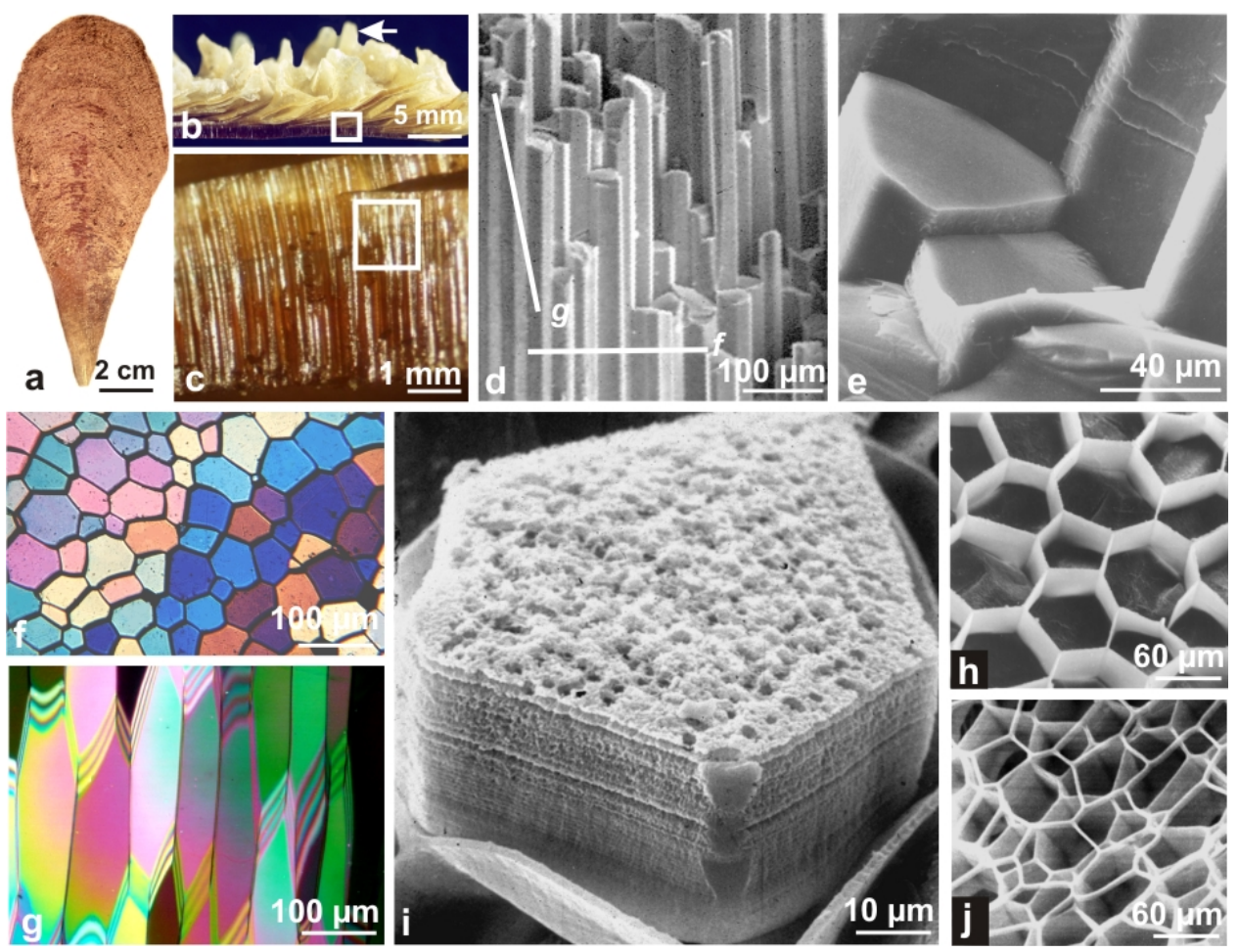

Credit pictures: d-f: [27], h: [28], i: [29], k: [30]. 
Figure 2. Simultaneous growth of organic envelopes and mineralized components of the prisms. (a,d) enzymatic etching $(\mathrm{a}, \mathrm{b})$ and acido-fixative etching (c) provide complementary evidence of a perfect synchronism in deposition of growth layers forming the prismatic outer part of the Pinna shells. Note that a stepping growth mode of envelopes is directly visible on their internal side. Figure $1 \mathrm{j}$ has shown that each growth layer can be separated from the others through soft hydrolysis process. (e-h) Calcitic prisms produced by Pinctada mantle also exhibit perfect synchronism in deposition $(\mathbf{e}, \mathbf{f})$. In addition, the stepping growth mode of envelopes is sometimes quite obviously illustrated, as here in the prismatic layer of a pearl bed (f,g). Using back scattered electrons, the high contrast between mineralized and purely organic parts emphasizes the morphological details resulting from the stepping growth mode $(\mathbf{h})$; $(\mathbf{i}, \mathbf{j})$ Microprobe distribution maps of magnesium and sulfur on a polished section in a Pinna shell. Section almost perpendicular to shell surface: prisms are cut in their length but slightly obliquely; $(\mathbf{k}-\mathbf{l})$ Distribution of sulfated polysaccharides by synchrotron based X-ray absorption of sulfur $(\mathrm{k})$ shows that prism envelopes (1: arrow) do not contain polysaccharides, although sulfur is abundant as shown by microprobe mapping (2j): envelopes are mostly protein made (see also Figure $3 \mathrm{~h}$ ). In addition the layered distribution provides additional evidence of the organic-mineral interplay within each growth cycle.

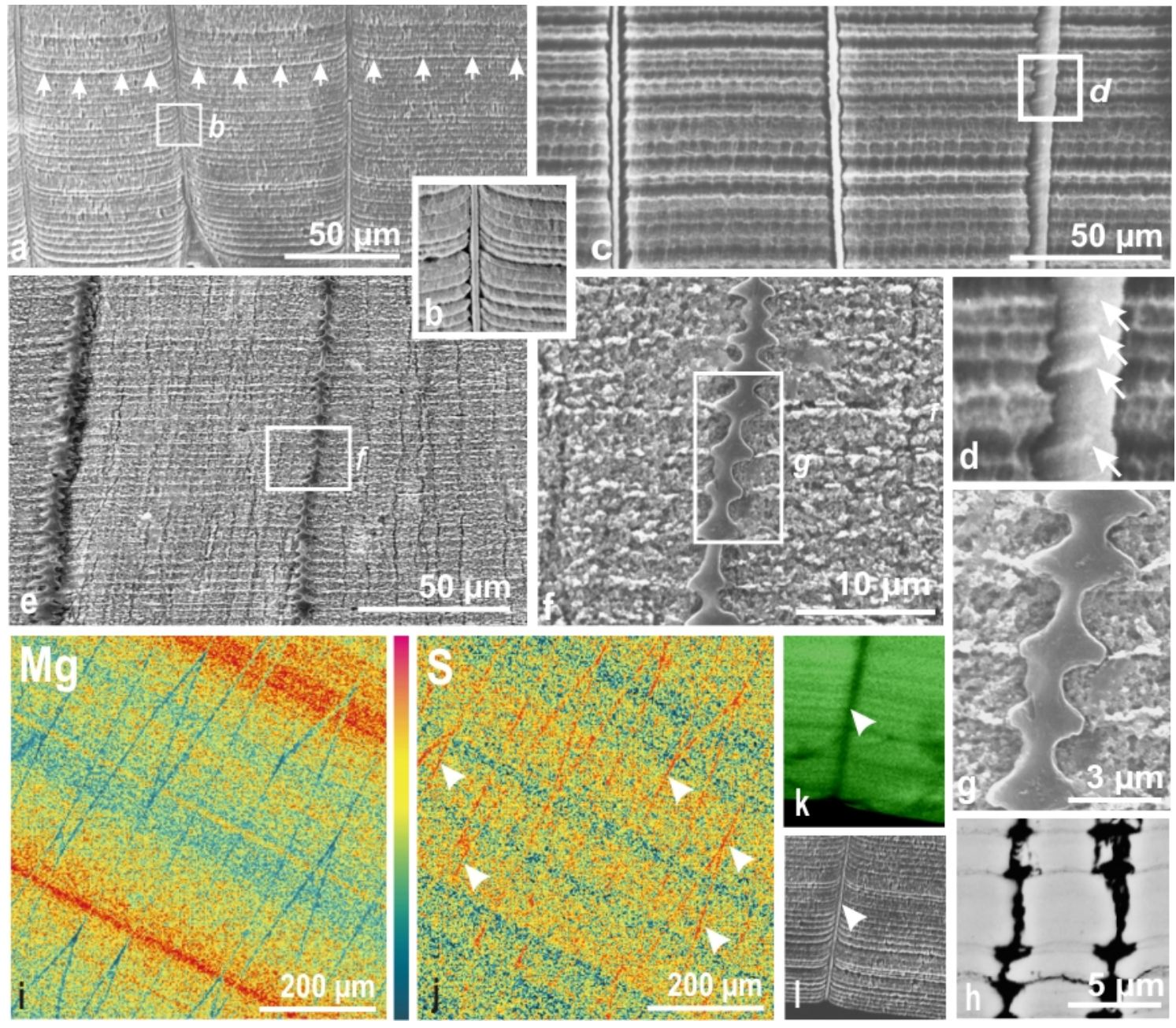

Credit pictures: a-c: [28]; e-g: [30]; k-1: [31]. 
Clearly, formation of the organic polygonal network is a part of the formation of each growth layer. With respect to timing of the growth layer formation, it is a reasonable assumption that envelope formation may occur at the beginning of the cycle, before crystallization of the mineral phase (the reverse formation order, the insertion of the polygonal envelopes within an already completed mineral phase seems difficult, from an obvious mechanical reason). Consequently, prism shapes depend on the regularity in superposition of the polygonal networks through the repeated micrometer-thick mineralization cycles. It must be noted that such a simple observation emphasizes the key-role of envelopes in the shaping process of the prisms, providing a counter argument to the commonly claimed "crystal growth competition" mechanisms as the origin of skeletal microstructures [32,33]. Little is known about biochemical complexity of prism envelopes (see [34] for review). Built mostly (if not exclusively) by proteins (see below Figure 3h), any change in biochemical composition of the set of molecules involved in the self-assembly process may result in morphological variation in the shape of the polygonal units. In some case this change in prismatic spatial organization of the polygons is clearly visible. Thus, modification of this self-assembly process due to compositional changes in the involved protein cluster will result in shape variations of the biomineral (Figure 5.9) [30].

Variations in chemical compositions of the superposed growth layers also illustrate the layered mode of growth for the prisms [31]. Electron microprobe mapping of magnesium (Figure 2i) or sulfur (Figure $2 \mathrm{j}$ ) on wide surfaces of shell sections clearly shows that variations in the chemical composition of the prisms remain strictly linked to growth layering all along shell formation. Additionally, these variations are distinct from one element to another one. Obviously (Figure 2i) changes of the magnesium content in the superposed layers are independent from variations affecting sulfur. This strict and permanent correlation between structural and chemical patterns implies a cyclical biomineralization mechanism whose secretion activity is synchronized at the animal level, or more precisely the whole mineralizing surface of the mantle producing the prismatic layer of the shell.

Attention must be drawn to the possibility (and importance) of identifying the chemical form (coordination) under which a given element is present in the growth layers. The example of sulfur is demonstrative: the distribution of sulfur in Figure $2 \mathrm{j}$ (microprobe mapping) shows a high content of sulfur (as a chemical element) in the envelopes of the prisms. Studying sulfur distribution using X-ray synchrotron allows specifying a given oxidation state by selecting energy of the XANES absorption peak (e.g., $2.4825 \mathrm{eV}$ as in sulfated polysaccharides).

Data (Figure $2 \mathrm{k}-1$ ) show that in the mineralizing organic phase of the prisms the sulfur is in the same oxidation state as in polysaccharides. No such polysaccharide-sulfur is visible in the section of the envelopes, which is a first indication that they are mostly built by proteins.

With respect to the model of crystallization within a liquid-filled crystallization chamber, the layered mode of growth of the prisms is remarkable from two respects:

- thickness of each growth layer is identical across the whole mineralizing surface of the growing prisms. The thickness of Ca-carbonate deposition does not depend as much on crystal orientation as it does on the faces of freely growing crystals in saturated solutions. In biogenic crystals this thickness is related to the secretion activity of the mineralizing epithelium.

- chemical composition of a given growth layer is strictly limited to a single layer, clearly distinct from previous and following ones. It must be taken into account that periodicity of the 
secretion process is sometimes very high. For instance growth layers in the calcite prisms of the gastropod Concholepas are deposited in up to 40 cycles a day, when nutriment availability is optimal [35]. Formation of micro-thick layers with such specific and rapidly varying chemical compositions is hardly compatible with large liquid volumes as pictured in current crystallization chamber models.

\subsection{Evidence of a Coordinated Stepping Growth Mode in Coral Fibers}

Coral skeletons (Scleractinia corals but not corals belonging to Alcyonaria or Octocorals) are mostly built by crystal-like fibers (always aragonite in modern corals) generally arranged in variously diverging fan-systems (Figure 4a-d). A long time before Lowenstam's classical statement of a "biologically induced crystallization" [23], such pictures had led Bryan and Hill [36] to suggest that a "spherulitic crystallization" was the main mechanism responsible for development of coral fibers viewed as "single crystals of orthorhombic aragonite".

Etching of polished surface of a fibrous fan-system of coral skeleton (Figure 4e-f) immediately disproves the Bryan and Hill concept of fibers freely growing to form spherulites as it occurs in purely chemically saturated solutions. Contrastingly, the growth pattern of fibers exhibits close similarity to the growth mode of the Pinna calcite prisms as seen above: far from individual and independent development of fibers, Figure $3 \mathrm{f}$ clearly shows that incremental growth is strictly coordinated between neighboring fibers. Additionally, thickness of the growth layers is identical on all fibers of the fan system, irrespective of their individual crystallographic orientation. Undoubtedly, the biologically controlled deposition mechanism imposes its specific rules to the growth of the fan system as a whole. Looking at etched and polished sections of entire coral septa (Figure $4 \mathrm{~g}-\mathrm{n}$ ) shows that synchronism of the stepping growth is even ensured on much wider mineralizing surfaces.

At the whole septum level, we can find structural evidences of a fully controlled mineralization of the skeleton in corals. When species-specific morphologies of the septa have to be obtained, the basal ectoderm of the polyp is able to modulate the thickness of the growth layers (Figure $4 m-n$ ). Microstructural evidence of this global control of the polyp on the corallite structure is a non-surprising result for coral taxonomists who were long familiar with close relationship between septum morphology, fibrous spatial organization and coral taxonomy [6,7,37].

Although fully illustrated in two examples only, this result establishes a full similitude in the growth mode between two skeletal units that were (and still frequently are) considered as representatives of two distinct types of biomineralization: the "biologically induced" coral fiber and the "matrix mediated" calcite prism of the Pinna shell.

Conclusion 1: From a structural view-point (micrometer scale), both calcite prisms of Pinna and aragonite fibers of Scleractinia corals exhibit evidence of a coordinated stepping growth mode. These skeletal units are built by superposition of mineralized layers basically continuous between neighboring units. Variations in thickness of these growth layers, strictly similar on the whole mineralizing area, provide demonstrative argument for a well synchronized metabolism of the mineralizing cell layer. 
Extensive investigation [30] suggests that a layered growth pattern is a very common mineralization method. Control of Ca-carbonate crystallization on wide areas but on thicknesses limited to the micrometer range seems the first level of a "common strategy" adopted by the various phyla creating a calcareous skeleton. Initially based on simple geometric evidences, this conclusion finds substantial support when considering the distribution of biochemical compounds permanently associated to the Ca-carbonate skeletal units (see figure 5 below). With respect to the use of calcareous skeletons as environmental archives, it is worth noting that each of these growth layers is the actual environment recording unit [38], an interesting conclusion owing to the continuous improvement of spatial resolution of analytical instruments.

Figure 3. Layered growth of the Pinctada shell at the micrometer scale: correspondence between mineralogical and biochemical layers. (a-d) View of the internal surface. The aragonite (A) and calcite (C) deposition areas (a: internal view; b; shell section) are separated by a thin organic sheet $(\mathbf{c}-\mathbf{d})$ which progressively covers the upper surface of the prisms (d: arrows). Consequently, prism growth is immediately interrupted (in contrast to scheme e, for instance); (e) Sections perpendicular to shell surface. In this model of common liquid chamber (redrawn from [12]) no explanation is given on how the mantle can control the simultaneous deposition of calcite and aragonite at the $d$ point; (f-i) The calcite-aragonite transition viewed on section perpendicular to shell surface. SEM secondary electron (f) shows the early deposition of aragonite (arrows) whereas SEM back scattered electrons imaging of this sector (g) reveals the general layering by emphasizing the contrast between organic and mineralized materials; $\mathrm{h}-\mathrm{i}$ : X-ray absorption maps of protein sulfur (h) and polysaccharide sulfur (i) by synchrotron XANES mapping on the same sector. Note the strict correlation between distribution of mineral phases $(\mathbf{f}-\mathbf{g})$ and inversion of protein and polysaccharide proportions between the two mineral components. Prism envelopes and covering organic layer are practically pure protein (deep red on 4h); (j) Laser confocal view of the calcite aragonite transition in a Pinctada shell. The daily growth doublets $(d g d)$ are well visible through fluorescence at $633 \mathrm{~nm}$ helium-neon laser illumination (Doc. A. Ball, NHM London, UK). Note their perfect parallelism even at the transition step, where last calcite is deposited on the right $(\mathrm{C})$ of the growth layer whereas first aragonite components are produced on left side (A); (k,l) Stepping development of nacre. After closure of the calcite compartment $(\mathrm{C})$ by the organic sheet, non-granular and fibrous aragonite (A) is produced first. It becomes true nacre only when parallel lamination occurs (arrows); k: occurrence of nacreous layering: nitrogen mapping using nanoSIMS (doc. A. Meibom, MNHN, Paris, France); 1: equivalent area viewed by BSE imaging: progressive occurrence of organic layering is also well visible; $(\mathbf{m}-\mathbf{p})$ Stepping development of nacreous tablets. Deposition and growth of nacreous tablets is simultaneously controlled on several layers, following a long recognized staircase scheme $(\mathbf{m}-\mathbf{0})$. Deposited at the forefront of each layer, the nacreous tablet centers $(\mathrm{n}: n t c)$, are progressively surrounded by concentric layers (p) (doc.: H. Mutvei). 


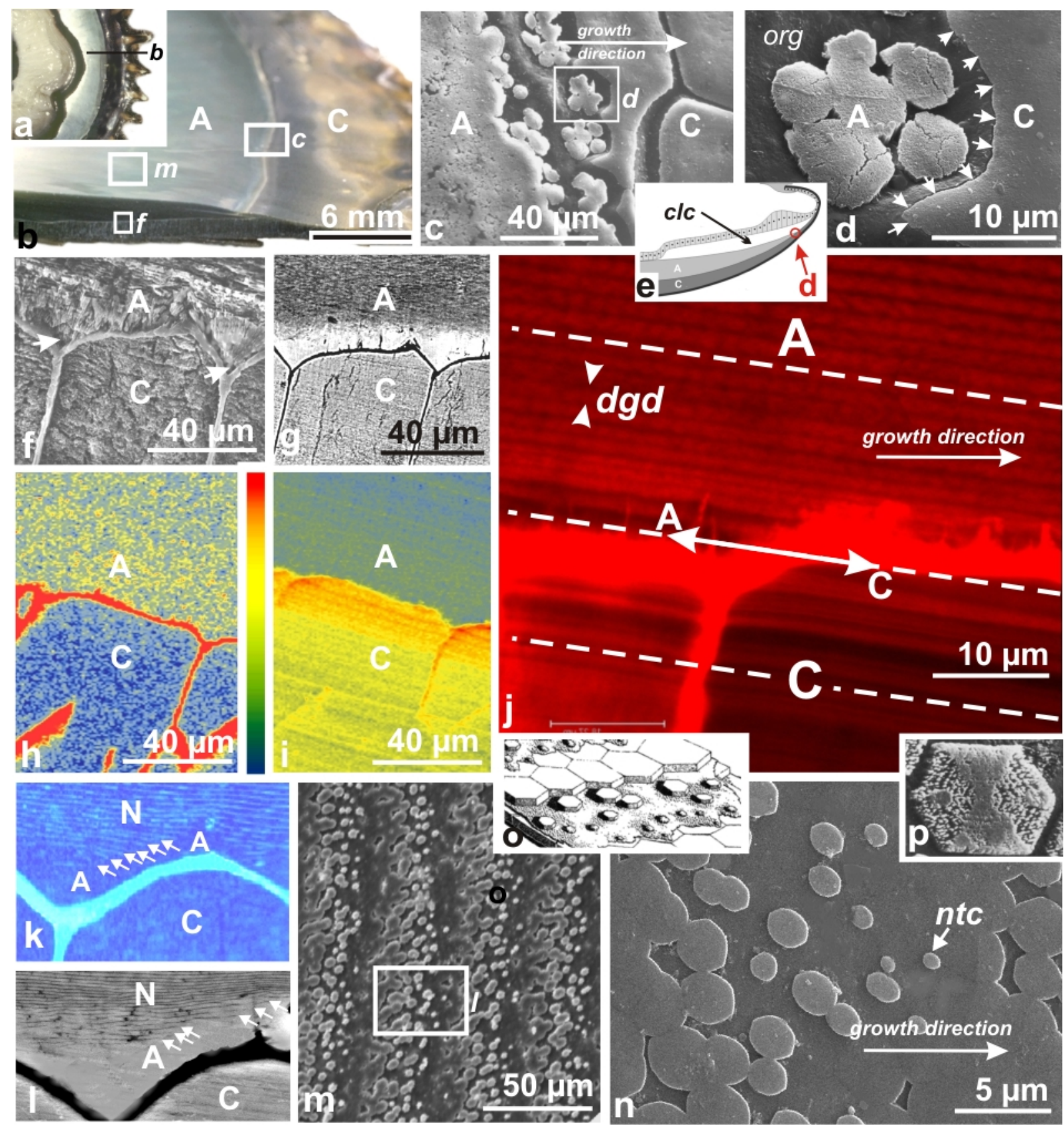

Credit pictures. a-c: [39]; e: [12]; f-i: [40]; j: [30]; k: [40]; o: [41]; p: [42].

Figure 4. Structural evidence for an overall control on the growth of coral fibers. (a-d) From skeleton morphology to fiber fan-systems in skeleton of a coral Porites; $(\mathbf{e}, \mathbf{f})$ Ultra-thin section of fan systems (cross-nicol polarized light) and etching of the same surface: continuity of growth layers emphasizes the common stepping growth mode for neighbor fibers. Note the regular thickness in deposition of a given growth layer whatever the crystallographic orientation of the substrate; $(\mathbf{g}-\mathbf{i})$ A polished and etched surface in the skeleton of a Pavona coral shows that the stepping growth is fully coordinated at the septum level: perfect continuity of the growth lines; $(\mathbf{j}-\mathbf{l})$ Similar growth-mode in the septum of a Favia corallite; $(\mathbf{m}, \mathbf{n})$ The specific morphology of septa in a given coral species is obtained by localized modulation of the thickness of the growth layers, as illustrated by the etched-surface of this Favia stelligera septum. 


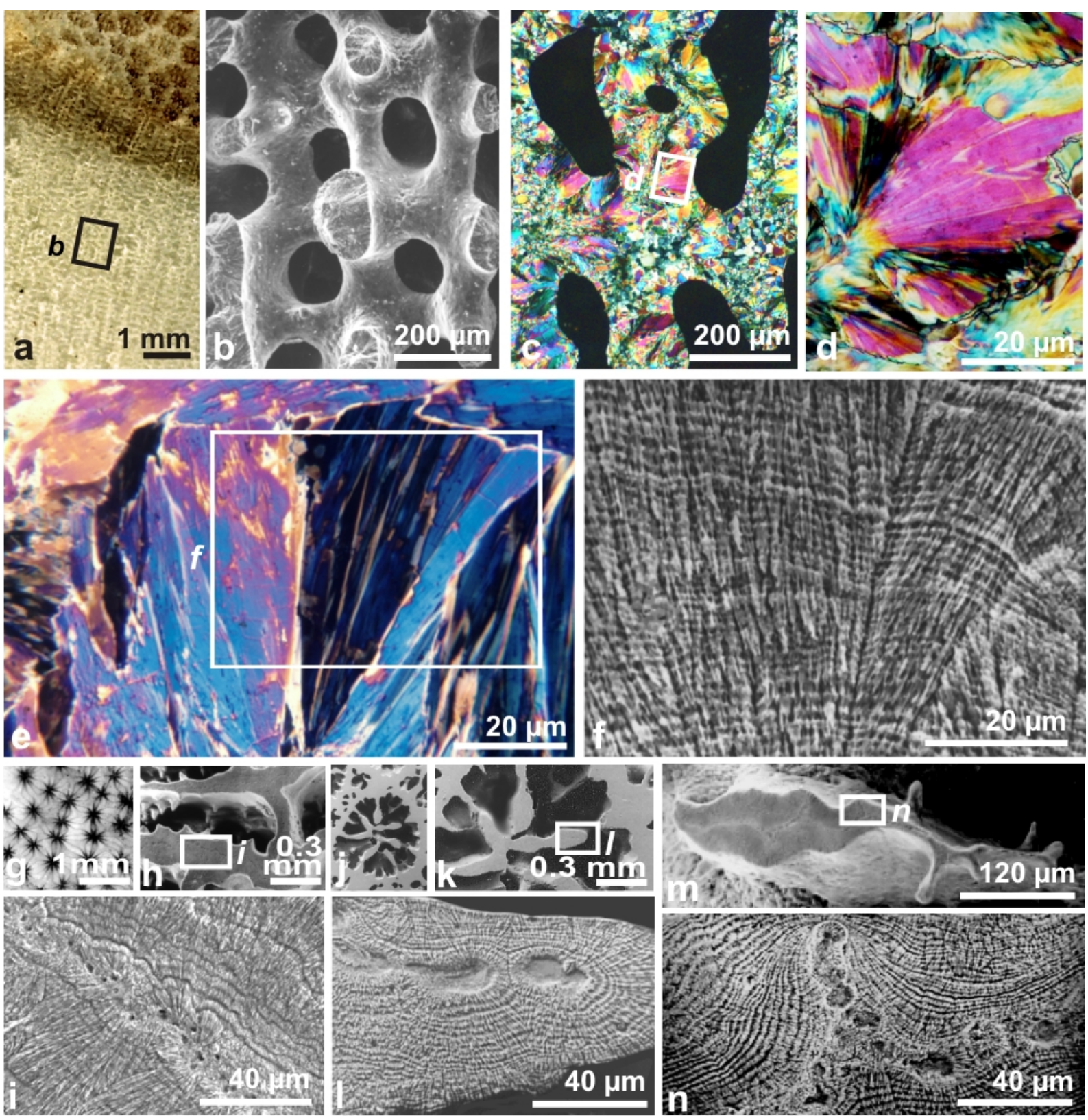

Credit pictures: e-f: [38]; i-n: [30].

\subsection{Concomitant Depositions of Distinct Ca-Carbonate Polymorphs with Specific Crystallization}

Patterns and Compositions: A Major Obstacle to the "Liquid Crystallization Chamber" Model

Independently of their taxonomic position (i.e., place in the evolutionary tree of life) most of the organisms producing calcareous skeletons built a microstructural sequence made by superposition of two (sometimes three) distinct types of Ca-carbonate built by specific microstructural units. When only calcite or aragonite is used, this sequence comprises two morphologically distinct types of skeletal units as exemplified by many Bivalve mollusks such as commercial oysters (Ostrea, Crassostrea). Scleractinian corals illustrate this microstructural diversification of aragonite skeletons as well as some Pelecypod families such as Trigoniidae or Unionidae. Modern gastropod families exhibit aragonite shells with highly differentiated microstructure, whereas ancient gastropod families such as Haliotidae and Patellidae use both polymorphs in various proportions. 
Considering models of crystallization in a "common chamber", a number of contradictory pieces of evidence are produced by a careful examination of these sequential skeletons. The correlation between structural and biochemical data is specifically demonstrative when calcite and aragonite are simultaneously involved as in the shells of Pelecypods (Bivalve mollusks) belonging to the Pteriidae family, among which Pinctada, the "pearl oyster", is the most studied. With an outer layer made of calcite prisms and a thick inner layer built by aragonite in the form of nacreous tablets, this large shell appears as a perfect illustration of the classical model of Bivalve shell, and (by extension) a model for all mollusk shells.

A close examination of the contact area between calcite and aragonite on the internal side of a valve (Figure $3 \mathrm{a}-\mathrm{d}$ ) shows that the very first aragonite components, on the form of granular round spots (Figure $3 \mathrm{c}-\mathrm{d}$ ) are not directly deposited onto the surface of the calcite prisms, but on a thin organic sheet progressively covering the prism growth surfaces (Figure 3d: arrows). Redrawn from the Volkmer's model [12], Figure 3e drives attention to the question of how a simultaneous and precisely localized precipitation of calcite (C) and aragonite (A) can be obtained by a mechanism of saturation within a common liquid chamber. Attention must be paid to the absence of permanent anatomical separation between the two mineralizing domains in the Pteriomorphids (the family to which the genus Pinctada belongs), a point that is correctly drawn in the Volkmer's scheme.

The biochemical control on deposition of the mineral phase of the two main shell components (prismatic calcite and nacreous aragonite) is illustrated by Figures $4 \mathrm{f}-1$. In addition to previous structural evidence, these various physical characterizations applied to the transitional area between calcite and aragonite domains show that specific organic components are associated to each of them.

With respect to the overall shell growth process, the layered pattern obtained by laser confocal fluorescence (Figure 3j) is of particular importance. This picture shows the perfect parallelism of the superposed mineralizing layers and the continuity between calcite and aragonite mineralizing areas in a given growth layer. Thickness increasing and simultaneous lateral expansion of the shell result from a single stepping process common for both the calcite and aragonite domains. Every growth layer comprises both calcite and aragonite deposition areas as assessed by the biochemical mapping: obviously, these clusters of mineralizing molecules, each of them specific to prisms or nacre have never been dispersed within a liquid crystallization chamber, but deposited in such a way that a very precise limit between the two domains is permanently maintained through the lateral expansion of the shell.

Initiated at the growing edge of the mantle, prisms grow in length by superposition of mineralized layers, up to coverage of their growth surface by the organic sheet (Figure 3b). Evolution of aragonite is more complex. Granular or fibrous aragonite is first deposited at the forefront of the aragonite area (Figure $3 \mathrm{c}-\mathrm{d}$ and $\mathrm{f}-\mathrm{g}$ ). Later, i.e., more internally with respect to the calcite/aragonite limit, or above when looking at transversal sections ( $\mathrm{f}-\mathrm{i}$ and $\mathrm{k}-\mathrm{l}$ ) the first nacreous tablet centers appear (Figure $3 \mathrm{n}$ : $n t c$ ) whose specific biochemical composition is now established [43]. Development of nacreous tablets follows the Erben's morphological sketch (Figure 3o) [41], but from a structural view point is also a layered stepping process (Figure 3p), as evidenced by Mutvei [42]. 


\subsection{Coral Skeletons are also Built by Superposition of Two Distinct Mineralization Areas}

A dual crystallization process can be illustrated also in the skeletons of scleractinian corals (Figure 5). In addition to aragonite fibers that form the main part of the corallites, a second crystallization domain exists, without exception, also producing aragonite crystals. This latter is made of randomly oriented tiny crystals [44]. Viewed from upper surface of the corallites, spatial distribution of the microgranular domains is very diverse but typical for each coral genus and biologically controlled, as shown by comparative molecular biology [37]. This is the reason why architecture of the coral septa is a first-rank taxonomical character at the genus and family level. Actually, the microgranular domain is always in median position in the coral septa, sandwiched between the lateral fibrous layers (Figure $5 \mathrm{~h}-\mathrm{i}$ and $51-n$ ). A remarkable agreement exists between these geometrical data and the pioneering observations of Vandermeulen and Watabe [45] on the development of mineralization in the post-larval growth of Pocillopora. A few hours after larval settlement, skeleton formation occurs first as a purely granular mineralization producing the first cycle of juvenile septa and circular wall. This early skeletal stage is followed by an additional layer of fibers on both sides of the granular framework. In spite of the complex morphological and structural evolution that has occurred in the coral Scleractinia since their origin in the Triassic time, extensive molecular investigation has shown that such a two-step mineralization process was preserved by scleractinian corals through formation of their evolutionary lineages.

The biochemical characterization of the organic components associated to the skeletal elements fully confirms the duality of the skeletal microstructure in corals. Synchrotron-based XANES mapping allows simultaneous characterization of the high polysaccharide contents (Figure $5 \mathrm{c}-\mathrm{f}$ ) of the distal mineralization areas [46]. Actually, these granular mineralization areas are the continuation of the first mineralization phase observed by Vandermeulen and Watabe. Simultaneously, the banding pattern of polysaccharide distribution (Figure 5f: arrows) is also made visible, polysaccharide layers corresponding to the successive calcification processes and stepping growth mode of fibers.

Thus, in addition to simultaneous crystallization of morphologically distinct aragonite skeletal units, a chemical property of coral skeletons demonstrates spectacularly the inadequacy of the common crystallization volume (named "sub-ectodermal space" in corals). Strongly different isotope fractionations or minor element concentrations between the two mineralizing areas have been firmly established by different technical approaches. It was firstly recognized on deep-sea corals, taking advantage of their remarkably simple organization. Desmophyllum a solitary coral (Figure $5 \mathrm{j}-\mathrm{k}$ ) has a size large enough to use the classical drilling method in order to separately collect calcareous material from the median mineralizing area and compare it to the lateral fibrous structures (Figure 51-m). Using this method, Adkins [47] found a considerable difference between the $\delta^{18} \mathrm{O}$ of these distinct mineralizing areas. Also recognized in Lophelia (another deep-sea coral) by using SIMS measurements [48] these properties were generalized to a wide diversity of Scleractinia [49] then extended to minor element concentrations [50]. Since this early evidence, equivalent results have been obtained each time that instruments with spatial resolution compatible to the sizes of the distinct crystallization areas have been used. 
Figure 5. Dual crystallization and environmental recording in coral skeletons. (a-d) The two mineralization areas in coral skeletons are illustrated here by a lateral view of a septum of a Colpophyllia coral (from Guadalupe, Caribbean archipelago): spines of the growing edge (a: arrows) produce short lateral branches appearing as granules of the septum sides (a: double arrows); SEM view (b) show the long recognized specific microstructure of these growing edge areas ( $\mathrm{b}: g$ ) well distinct from fibrous tissues (b: $f=$ fibers seen from their distal tips); (c-e) Synchrotron-based XANES mapping in a Montastrea corallite. c: Morphology of the corallite; d: polished surface on the sample holder; e: studied surface under UV illumination to locate the distal mineralization areas (microgranular); f: distribution of sulfur from sulfated polysaccharides by XANES method: note the higher content in polysaccharides of the median mineralizing areas and the clearly visible banding pattern in the fibrous area (black arrows). ma: microgranular area, $f a$ : fibrous area; (g) Etching made after XANES mapping reveals the skeletal microstructure of the corresponding area: tiny microgranules of aragonite $(\mathrm{ma})$ are visible in the median (=distal) area, as well as the stepping growth mode of fibers on both sides. $(\mathbf{h}, \mathbf{i})$ Scheme of the stepping growth-mode of a coral septum, viewed from a section perpendicular to the septal plane. ( $\mathbf{j}-\mathbf{m})$ Difference in $\boldsymbol{\delta}^{18} \mathrm{O}$ between the two distinct mineralizing domains (median area made of tiny granular crystals and fibers, on both sides of the median area) in the septum of a Desmophyllum; (n-o) Either continuous (n: section in a septum of a Favia corallite) or discontinuous as in the skeletons of the Porites colonies (o), a significant differences in isotopic fractionation or minor element partitioning is always found between microgranular and fibrous mineralizing areas. In 5o, ellipses exemplify how sampling positioning may result in important dispersion of the measured values depending on the proportions of the two distinct mineralizing areas involved in the measurements.
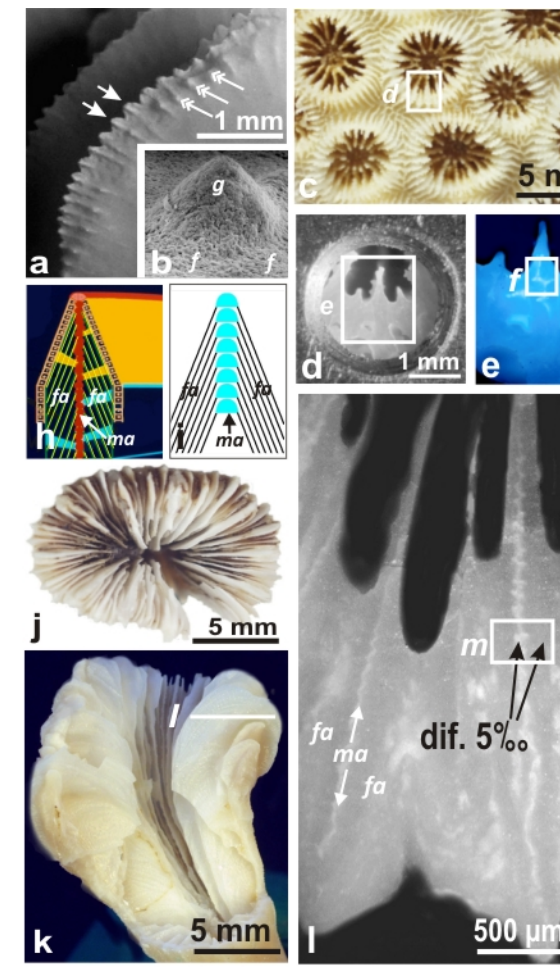

Credit pictures: c-g: [46]; n-o: [49].

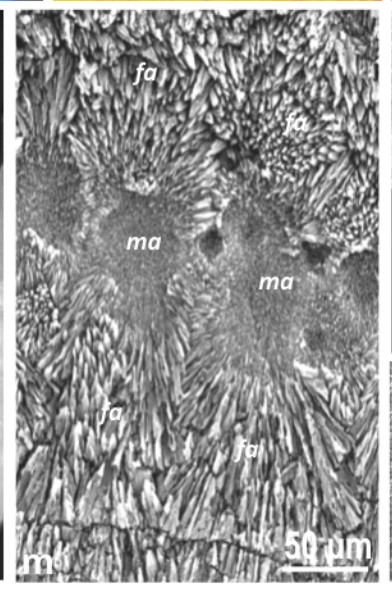

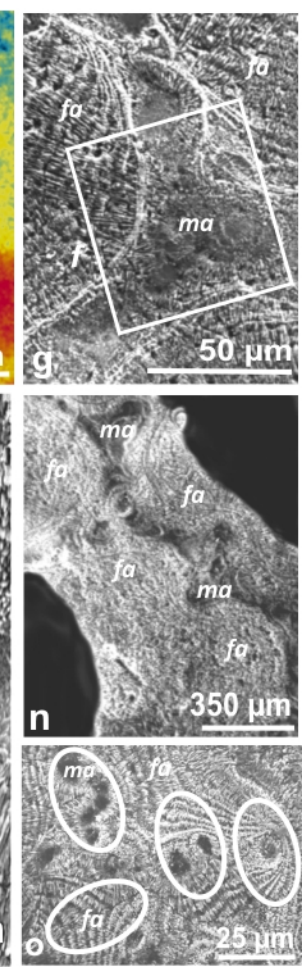

$$
\text { . }
$$


In addition to their importance in paleo-environmental studies (measurements must be made on microstructurally homogenous areas), these differences in isotopic fractionations and minor element concentrations between the distinct crystallization areas of a given coral skeleton is also demonstrative of the inadequacy of the "common liquid chamber" (or "sub-ectodermal space" model for crystallization of the skeleton units. A spatial distribution of chemical or isotopic properties between the two mineralizing domains of the skeleton (both aragonite in this case) is not possible if crystallization has occurred within the classically hypothesized "common liquid chamber".

Conclusively, such a close correlation between mineralogy, microstructure, biochemistry of mineralizing matrices up to minor element concentrations and isotope fractionation of the mineral phase fully disprove the hypothesis of crystallization occurring within a common liquid chamber located between the mineralizing organ and the growing mineral surface. In other words, this implies that during the mineralizing phase, a close contact must exist between skeletal surface and the epithelial cell layer. These structural and chemical converging results fully confirm the Clode and Marshall's observation of a close contact between coral skeleton and the overlying basal epithelium of the polyp [51].

Conclusion 2: Structural and chemical investigations bring converging results disproving the possibility of a common liquid-filled chamber between the mineralizing cell layer and the mineralized surface of the growing skeletons.

Remarkably, two similar conclusions were drawn several decades ago by independent investigators. Miles Crenshaw, who made important contributions to the knowledge of organic components involved in crystallization of biogenic Ca-carbonates was for a long time working on the composition of the "extra-pallial fluid". Considering his results and those of co-workers using similar analytical approaches, he wrote a singular statement fully diverging from the common opinion: between the mineralizing organ and the inner shell "the transfer of material is essentially direct" [52] (p. 120).

Some years before, Wilbur (Figure 1) [53] (p. 244) had presented an equivalent view under a graphic form: a precise sketch of spatial relationships between mantle and shell of a prismatic/ nacreous bivalve mollusk. In contrast to the above cited schemes (all more recent than Wilbur's one), the outer mantle epithelium is drawn very close to the whole surface of the inner shell. Actually, Wilbur also used the expression extra-pallial fluid and was interpreting the shell structure in term of alternating organic and mineral layers (Figure 2) [53]. However, in Wilbur's figure, the space dedicated to "precipitation" was about 1 micrometer in thickness, which is typically the thickness of the organic gel at the moment where crystallization occurs. A third (and even older) example is found in the 1933 study of Kessel [54] of the structure of a gastropod shell (Vivipara viviparus) in which the layered structure of the shell is interpreted as evidence for a cyclic mineralization process producing the most geometrically complex and well ordered microstructure (crossed-lamellar), the formation of which as a freely growing process within a liquid chamber cannot be conceived without a tight control of the mineralizing organ. Remarkably, it was also in the $80 \mathrm{~s}$ that Johnston, after a careful investigation of coral skeletons, wrote that the proposed models involving organic compounds in biomineralization or experimental approaches were carried out "in ignorance of this material's spatial distribution and micro-architecture within the skeleton" [55,56]. It is also a major change in 
biomineralization studies that newer methods of observation and measurements now offer a positive perspective for investigating this key question.

\section{Nano-Structure of the Growth Layers: The Second Component of a Common "Basic Strategy" for Controlling Ca-Carbonate Crystallization}

Additional support to the Wilt and Ettensohn hypothesis of a "common basic strategy" is brought by the recent application of atomic force microscopy (AFM) to invertebrate skeleton structures. The very first AFM observations of biominerals was carried out in 1991 and immediately demonstrated that this method enables a description of mineral lattices at the atomic length-scale [57]. The authors of these pioneering investigations clearly exposed that such a new physical approach of biogenic composite materials (they used aragonite from clam and calcite from sea urchin) should allow direct observation of molecular relationships between organic and mineral components in biominerals. At that time, biochemical complexity of organic phases involved in biomineralization processes was not fully evaluated. In the concept of an organic framework made of some polymer completed by a restricted number of additional organic molecules, the perspective of a direct recognition of organo-mineral architectures at the molecular length-scale, or even "studying in situ processes, since imaging is also possible under liquids" was a reasonable perspective. Essentially, such a statement remains valid but biochemical complexity of the organic phases in biominerals makes a direct identification of the involved molecules as well as a reconstruction of their function in the mineralization process inaccessible. However, owing to remarkable methodological diversification, AFM took a key-role in biomineralization studies by revealing an unexpected structural status of the growth layers, leading to reexamination of the crystallization process itself.

\subsection{AFM Intermittent-Contact Mode (Tapping) and TEM Diffraction Data Suggest a New Model for Biocrystallization}

Between the molecular level and the micrometer length-scale investigations, information collected by AFM tapping-mode has shown an unexpected distribution of the two main components of the Ca-carbonate skeletons: the mineral phase and the associated organic component. It is worth remembering that if envelopes of biominerals are easily visible by scanning electron microscopy (SEM), specifically by using the back scattered electron mode (BSE), the position of the organic compounds associated to the mineral phase (usually known as "soluble matrix") is far from well established. Of particular interest regarding the AFM tapping-mode is the ability of the instrument to record a "phase signal" generated by interactions between the studied substrate and the vibrating tip. Depending on local variation of physical properties of the material (such as adhesiveness, elasticity, viscosity, etc.), the actual position of the vibrating tip generally differs from its theoretical position as generated by the vibration frequency. Thus during the surface scanning process a phase-lag signal can be recorded, linked to the physical properties of the studied substrate. When applied to calcified growth layers, the phase-contrast imaging mode reveals an unexpected heterogeneity pattern of the mineralized layers.

Figure 6 shows a series of AFM maps of phase-lag distribution obtained from polished sections of calcite and aragonite samples from coral and mollusk shells. At comparable enlargements (in the $\times 10$ 
nanometer range), these materials show an interesting similarity with respect to the contrast between zones of highly interactive materials (dark areas) and zones of much weaker interactions (light grey). Attention must be paid to mineralogical and biochemical differences between these materials, established through considerable amounts of literature [30]. However, irrespective of these mineralogical or biochemical differences, a closely similar pattern appears in the distribution of interactive/non-interactive areas among all these materials. Highly interactive areas form an irregular reticulate network surrounding areas showing a much weaker phase contrast, i.e., less influential on vibration of the tip. With respect to the physical origin of the phase-lag signal we can reasonably assume that the more interactive areas correspond to higher concentrations of organic phases.

Figure 6. Uniformity of the reticulate pattern in mollusks and coral skeletons at comparable enlargements. (a) Calcite prisms of Pinctada; (b,c) Aragonite from the nacreous layer: phase-lag mapping (b) and same surface viewed in amplitude mode, an AFM tapping mode that emphasizes the changes in surface slopes; (d) nacre of a Pinctada pearl. This signal is the direct expression of surface topography. The spheroidal surfaces of the skeletal units are clearly visible. High resolution SEM pictures are now able to provide equivalent data; (e) Aragonite of a Scleractinia coral skeleton (Favia); (f) Organ-pipe coral (Tubipora), a calcitic Alcyonaria; (g,h) The white coral (Corallium johnsoni): another calcitic Alcyionaria; (i) The blue coral (Heliopora coerulea), the only aragonitic Alcyonaria; (j-l) The red coral (Corallium rubrum). This species remarkably exemplifies the post-depositional evolution of the organo-mineral material of the skeleton, leading to formation of wider units $(\mathbf{j}, \mathbf{k})$, whose spatial arrangement are irrespective of the layered growth process.
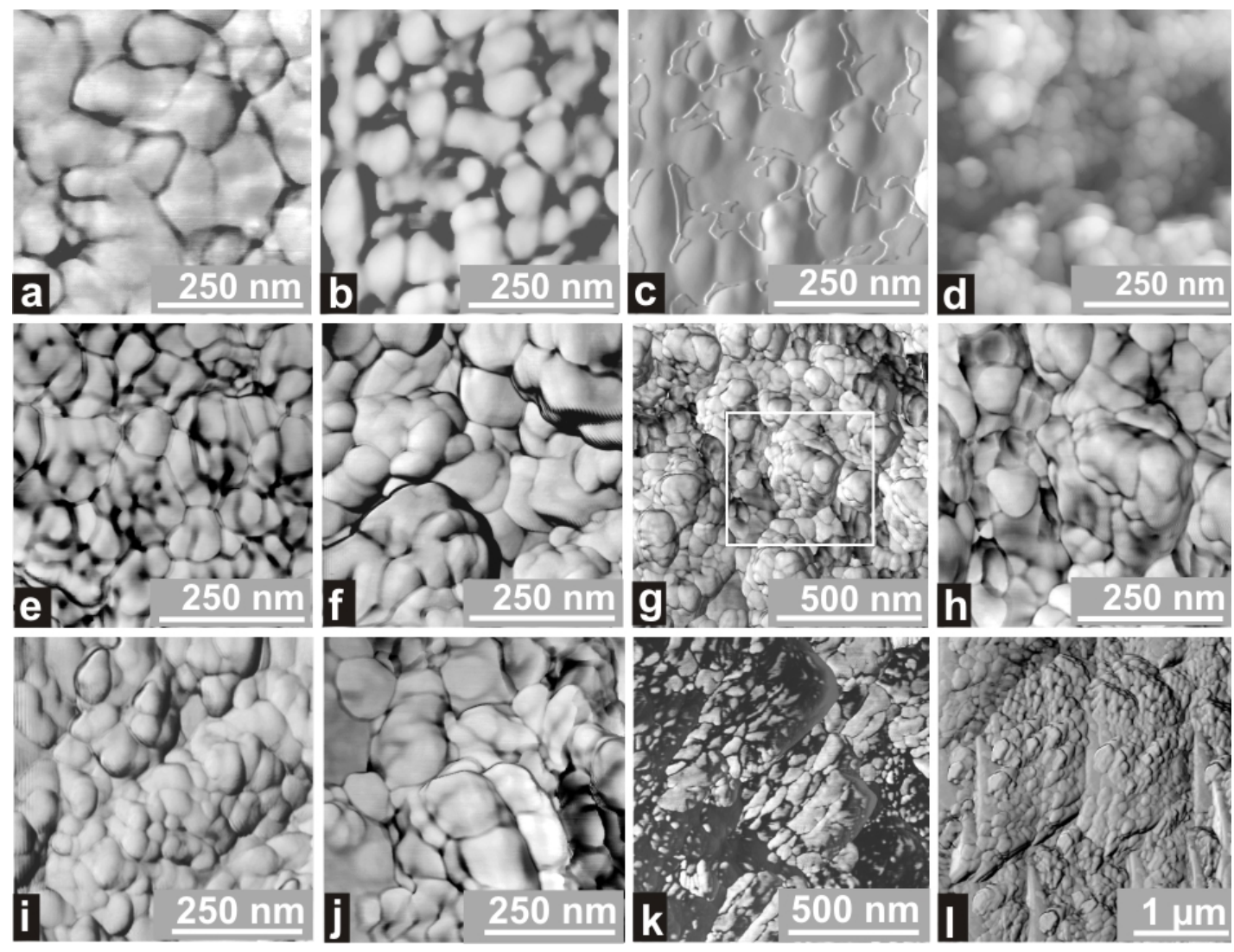
Taking into account the spatial distribution of these organic concentrations, as resulting from AFM mapping, the common reticular patterns to be interpreted clearly disagrees with the two current general models of biocrystal growth: the "template model", in which organic and mineral layers are regularly alternating, and the "molecular shaping" model. In the latter, organic molecules are dispersed within the mineral phase because they are individually influential on the growth of the mineral lattice whereas in the former, sheets of organic compounds (ideally Langmuir's mono-layers) act as substrates for nucleation and oriented growth of layers of purely mineral crystals. From an historical view point, the "template model" can be related to the discovery of organic membranes in Ca-carbonate skeletons by Gregoire [26] whereas the "molecular shaping" model of biocrystal growth is relevant to the 1972 Crenshaw's discovery of "soluble matrices" [58], admittedly closely linked to the mineral phases.

Such a reticular pattern, closely similar among phylogenetically distant organisms, provides additional evidence that the mode of crystallization of the mineral phase within each growth layer was not the typical mode of crystallization of Ca-carbonate within a saturated aqueous solution. It must be noted that no indication of facetted crystal development can be found on the uniformly spheroidal surfaces forming the reticulate structure. In order to improve our data about what appears as a specific pattern of crystallization, further investigations were carried out in order to reach the internal structure of the spheroidal units forming the mineral phase.

\subsection{Crystallization as a Final Step in the Cyclic Mineralization Process Forming the Growth Layers}

As Johnston [55] pointed out, "no reliable model of growth process can be proposed since analytical data cannot be correlated to structural observations carried out at relevant scale". Applying transmission electron microscopy to Ca-carbonate layers brings significant information owing to the ability of TEM to associate imaging and diffraction with very high resolution [59]. Observing the elementary components of the reticulate network at its growth (Figure $7 \mathrm{a}-\mathrm{c}$ ) shows that the last developed grains exhibit a well crystallized structure in their central part whereas the peripheral regions are amorphous (Figure 7d-f). Formation of lattice planes in the internal part of the reticulum (Figure $7 \mathrm{~d}$ : arrows) makes the development of the crystallization process obvious.

Figure $7 \mathrm{~g}$ summarizes the possible sequence of events forming a growth layer, based on the previous data. When a growth layer has just been completed, the mineralizing epithelium is in close contact with the mineral surface (Figure $7 \mathrm{~g} 1$ ). Formation of a new growth layer begins with secretion of an apparently non mineralized layer (Figure $7 \mathrm{~g} 2$ ). The earliest mention of such a translucent pellicle was made by Bourne [60], when studying the contact between coral skeleton and basal ectoderm. Goreau [61] was also able to characterize an organic layer in the identical position. In Pelecypod bivalves, the internal surface of the periostracum membrane is progressively charged by organic compounds during its transit along the cell layer of the internal lobe of the mantle, creating the initial organic layer that will ensure mineralization at the growing edge of the shell.

Existence of a gel phase as a general mechanism for deposition of the material to be mineralized find strong support in comparison of isotopic fractionation between waters extracted from the organic phases of mollusk skeletons and the waters where these organisms were living. According to Lécuyer and O'Neil [62] who carried out these measurements, the strong differences in $\delta^{18} \mathrm{O}$ between these waters demonstrate that waters extracted from biogenic Ca-carbonates are purely physiological in 
origin. This conclusion is strongly supported by the presence of water bound to the organic components in various invertebrate skeletons, as shown by thermo-gravimetric measurements coupled to infra-red absorption [63].

Figure 7. Illustration of a transition from amorphous to crystallized status at the growth front of the reticulate biocrystal $(\mathbf{a}-\mathbf{f})$ and scheme of the depositional and crystallization cycle forming a growth layer $(\mathbf{g})$. 7a-e: Internal surface of the calcite prisms at the forefront of a growing edge of a calcite prism (Pinna), showing the partly stripped gel layer (a) and the underlying surface of the growing prism (b); TEM observation of the grains (c,d) provides a view of what can be the transition between amorphous status of the gel-layer and crystallization of the Ca-carbonate (double-headed arrow). TEM diffraction patterns clearly oppose amorphous (e) and crystallized areas (f). Arrow heads underline the well ordered arrangement of crystallized area; $7 \mathrm{~g}$ : Schematic view of the depositional sequence of a growth layer. When the cycle is starting the mineralizing epithelium is in contact with the last formed growth layer (g1). The mineralization process does not involve any liquid space: separation of the cell layer from the mineralized structure results from secretion process, producing an organic-hydrogel layer, with thickness in the micrometer range (g2-g3). 7h: Synchronized crystallization process within the gel-layer may occur when the relevant thickness is reached (with local modulation): Mg banding pattern mapped from coral fibers suggests that a chemical signal may trigger the process.
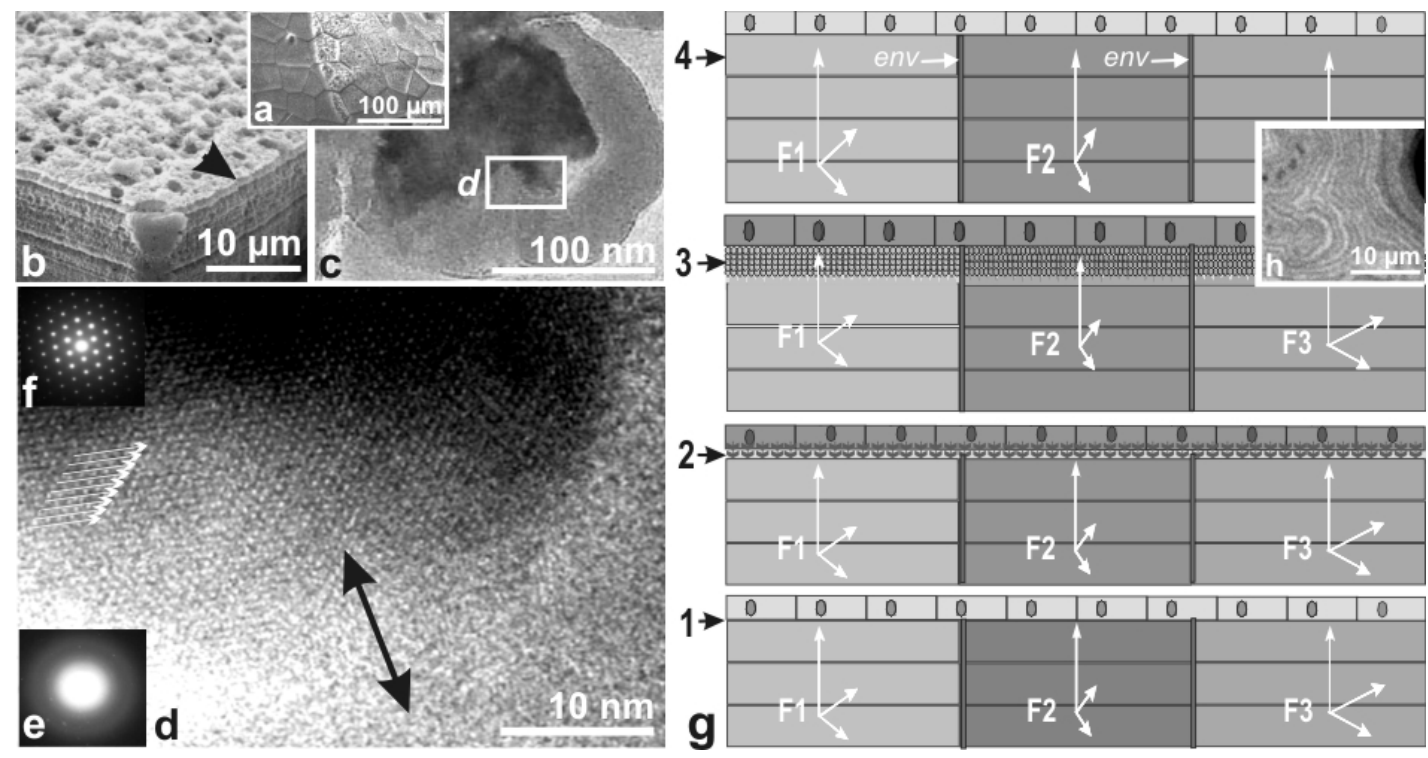

Credit picture: c-h: [58]; g-h: [30].

After the Beniash's discovery of amorphous calcium carbonate as a transient phase in the mineralization process [64], numerous occurrences of a similar material were found. Although no evidence has been presented yet for secretion of such amorphous calcium carbonate through the cellular membrane, formation of the micron-thick layer of organic hydrogel including amorphous calcium carbonate-probably stabilized by some organic component of the gel-is clearly in agreement with other evidences of a layered calcification process. 
Microprobe mapping of magnesium showing a spectacular banding pattern (Figure $7 \mathrm{~h}$ and [30], Figure $4 \mathrm{~m}$ ) suggest a possible chemical signal, acting as crystallization trigger on the whole mineralizing surface. In this view, the link between organic molecules carrying the mineral phase is disrupted, allowing crystallization to occur. Within the micron-thick gel layer crystallization spreads up to the lateral limits formed by envelopes. In this last step of the biomineralization cycle the mineral reticulum is formed. As a consequence of the crystallization process, the organic phase which was stabilizing the amorphous mineral material is pushed out at the periphery of the growing mineral lattice, producing the irregular organic coating of the mineral reticulum as illustrated by AFM phase-contrast imaging. Numerous interrogations persist about this hypothesized last step of the mineralization process. Noticeably, crystallization of Ca-carbonate as the most concentrated form of the mineral ions could lead to a reduction of the thickness of the gel layer. A fraction of the initial water remains associated to the organic components (as shown by ATG measurements [63]). On the other hand, imperfect segregation between organic and mineral components may occur, leading to the distorted lattices observed by Pocroy [65]. With respect to biological control on mineralization, attention must be drawn on the strict constraints imposed to the development of the crystallization process by the limited dimensions of the mineralizing volume: micrometer-range thickness of the mineralizing layer and, within a given layer, presence of the insoluble envelopes limiting lateral expansion of the crystallization process.

From a geometrical view-point this model typically corresponds to the "compartments and envelopes" bio-mineralization mechanism [66] but including new data which lead to re-examination of the respective roles for both soluble and insoluble matrices.

Regarding the role of organic envelopes as a limiting factor in lateral expansion of crystallization, it must be noted that a contrasted status is observed throughout species or even between shell layers of a given species. In mollusk shells, for instance, the well defined morphology of the prisms of the outer layers (generally perpendicular to shell surface) is due to the robust polygonal meshes formed in each growth layer and regularly superposed. However, in the microstructural units of the internal shell layers (e.g., foliated or nacreous), whose growth is also a stepping process [42], envelopes are much weaker, resulting in crystal-like morphological patterns frequently visible at the growing end of each microstructural unit. Since the first TEM pictures made by Wada [67] numerous examples of these angular borders have been presented as illustrations of a purely crystalline growth. However, examples are also abundant of "non-crystalline" morphologies (e.g., round shaped nacreous tablets from Wada himself [66] and this study (Figure 3n)). From a crystallization view point, no exception has been found to the presence of the "reticulate pattern" even within the most crystal-like units (Figure 4h-i) [30]. In addition, no data has been found so far suggesting that the microstructural units may result from assemblage of "mesocrystals" in the Cölfen [68] or Cölfen and Antonietti sense [69] as a preliminary stages for crystallization of the growth layers.

Thus, far from crystallizing in wide common liquid chambers, biominerals are developed through strictly controlled spaces, from both geometrical and compositional view points. No "close to sea water" liquid volumes exist at any step of the mineralization cycle. When a biomineralization cycle is close to its last step (crystallization), a gel layer (the thickness of which is in the micrometer range) separates the mineralizing cell layer and the "inner surface of the shell". This series of data fully justifies both the Crenshaw's statement [52] as well as observations of the cited early investigators. 


\subsection{Presence of a Nano-Scaled Reticular Pattern in the Calcified Structures Built by Brachiopods,} Echinoderms and Foraminifers

In several major biological groups obvious reasons make the sub-epithelial crystallization chamber model irrelevant. Foraminifera, for instance, are unicellular whereas in the whole phylum Echinodermata the skeleton is produced by the mesodermal tissue. In the Brachiopods, which build bivalved shells basically distinct from mollusk shells from morphological and architectural view point, a mineralizing epithelium exists but William's investigations [70] have shown that each of the shell forming fibers is produced by a single cell in the Rhynchonelliform brachiopods (formerly Articulata, i.e., the main part of the phylum). Only at the outer part of the shell an irregular prismatic layer is not so precisely driven.

Although extremely important, specifically when taking into account their fossil representatives, these groups are far less studied with respect to their mineralization process. What is remarkable is that in these three distinct phyla, the Ca-carbonate skeleton viewed at the nano-scale exhibit a strikingly similar structural pattern: densely packed nodular units of a few tenths of nanometers in maximum length.

Individually secreted brachiopod fibers of Rhynchonellid brachiopods exhibit an obvious stepping growth mode (Figure 8a-d). Their mono-crystalline pattern is beautifully exposed by EBSD method (Figure 8e) in spite of a clear nodular ultra-structure of the mineral phase (Figure $8 \mathrm{f}-\mathrm{g}$ ). As in any other synchrotron-based XANES characterization using a $1 \mu \mathrm{m}$ spatial resolution stepping process, distribution of the organic phases appear closely superposed to the mineral one [71]. Skeletons of Foraminifera provide also good examples of a clear banding pattern of the organic components obviously similar to layered structure of the mineral part (Figure $8 \mathrm{~h}-\mathrm{m}$ ). Presence of a nodular sub-micrometric structure in the crystal-like units is also visible (Figure $8 \mathrm{n}-\mathrm{o}$ ). Even in the phylum Echinodermata, whose perfect crystallinity of the skeletal component is long recognized (Figure 8p-q), the common reticular pattern of the mineral phase is clearly visible, without any trace of facetted units at the nanometer scale.

Figure 8. Reticulate structure of the Ca-carbonate skeletons in three other invertebrate phyla. (a) SEM image across the shell thickness in the anterior region of a dorsal valve of the brachiopod species Terebratalia transversa, showing the presence of fibers and endopunctae; (b-d) SEM views of calcite fibers in Rhynchonellida brachiopod (Gryphus). On longitudinal sections (b,d), etching clearly reveals the stepping growth mode. E: transversal section of fibers; (e) EBSD crystallographic map within the secondary layer of Terebratalia transversa (anterior region of the dorsala valve), showing longitudinally (I) and transversely (t) cut fibers, with a single crystallographic orientation for each fiber; (f,g) AFM pictures of the Gryphus fibers on longitudinal sections. At low enlargement the layered arrangement of the spheroidal units is still visible, whereas a closer view (g) illustrates their basic morphological similitude with those of other invertebrate calcareous skeletons; (h-o) Mineral and organic layering in the shell of Foraminifera. Optical (h,i) and SEM (j) pictures of Globorotalia tumida illustrate the long recognized layered organization of the shell. XANES mapping makes obvious the correlated banding pattern of the organic components: S-polysaccharides (k-m) and proteins (l). AFM allows morphological 
characterization of the spheroidal units (here in the contact mode, no phase-lag signal as on previous pictures which were obtained by using tapping mode); (p-r) Fracture surface of a sea urchin spine viewed at the SEM in imaging mode (secondary electrons) showing the non-facetted surface (p), although EBSD crystallographic map of a nearly transverse section of the same spine, perpendicular to the $c$-axis demonstrate a single calcite crystal behavior (q). AFM observation confirms that, as in all previous examples, echinoderm skeletons are made of nodular sub-units producing an overall reticular pattern.

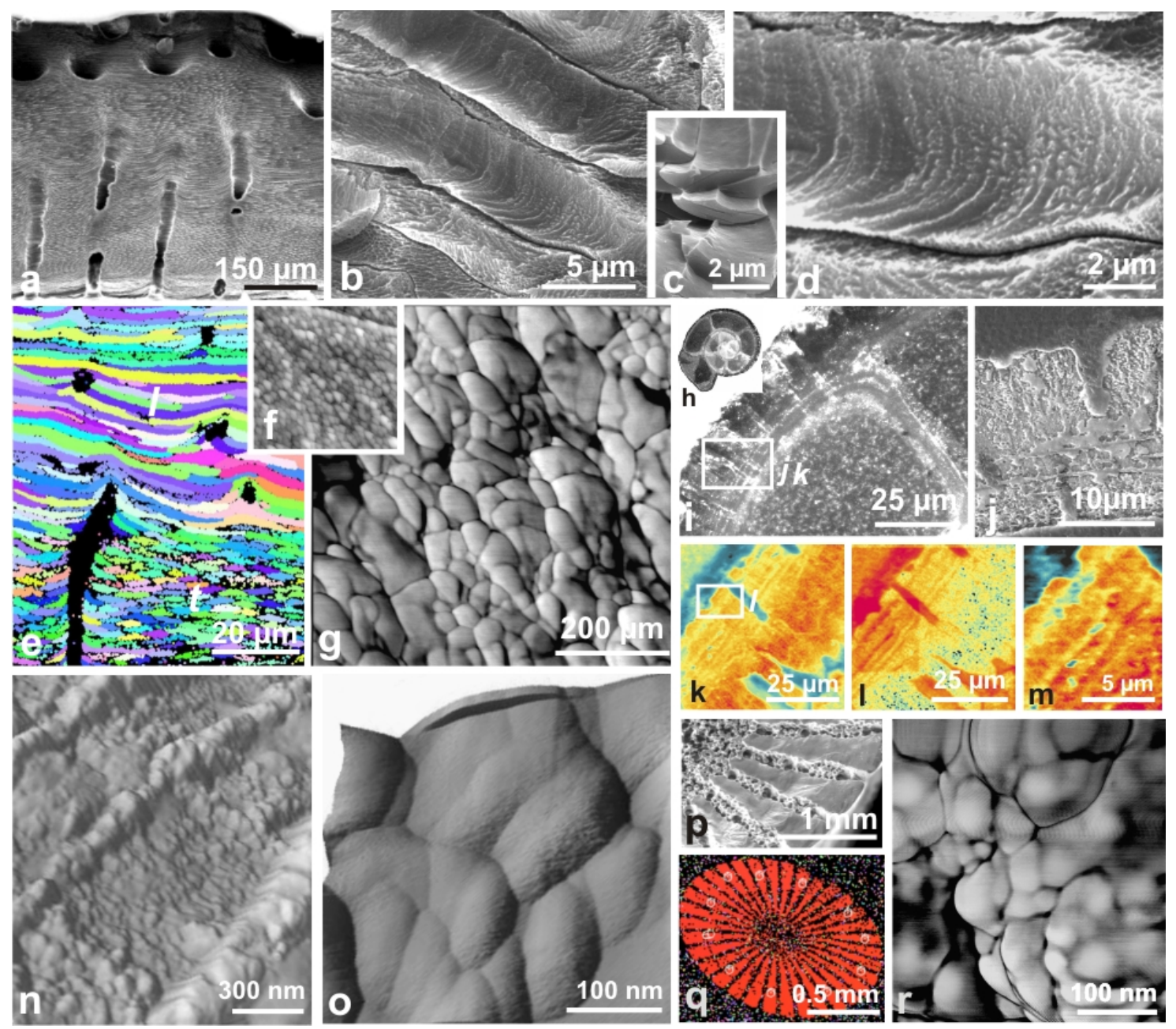

Credit pictures: a, e: [70]; b, d, p: [30]; f-g: [72].

Although obviously not involved in the discussion of a "common liquid chamber" model, similarity in the sub-micrometric structures of the skeletons built by these phylogenetically distinct organisms strongly suggests that the common reticular nanometer-scaled network may actually represents the most fundamental aspect of the common strategy hypothesized by Wilt et al. [21,22] to control the crystallization of Ca-carbonate unit. At an upper level of control, it can be noted that through different biological processes depending on general organization of each phylum, a stepping growth mode of skeletons and skeletal units seems to be present in these three additional examples. Brachiopod fibers exhibit a micrometer-scaled stepping growth mode (Figure $7 \mathrm{a}-\mathrm{d}$ ), the layered structure of the tests of Foraminifera was made obvious as early as 1955 [72] whereas etching of echinoderm skeletons also provided evidence of a cyclic mineralization process (Figure 11.3) [22] and control of functional specialization [73]. Conclusively, whatever anatomical organizations and the type of tissue involved in 
formation of the skeletons, mechanism allowing organisms to build the species-specific morphology and architecture of their mineralized hard-parts have developed extremely convergent mechanisms based on a coordinated stepping growth mode and a crystallization process that results in the common reticular pattern of the mineral phase.

Two recently published papers bring interesting data regarding the generalization of these results and their practical importance. Through a careful analysis of the Raman signal obtained from specimens of the Blue Coral (Heliopora coerulea), Zhang et al. [74] were able to retrieve the environmental information recorded on a daily scale in the aragonite fibrous tissue through chemical characterization of the skeletal growth layers. As a first application of the concept of "environment recording unit" [38], this methods opens a fascinating perspective for reconstructing recent evolution of sea-water chemistry. At the opposite end of the analytical scale for biogenic Ca-carbonate crystals, Nouet et al. [75] investigated by TEM (imaging and diffraction) the mode of crystallization of the spheroidal granules forming the reticulate structure in the crossed-lamellar tissue of a gastropod shell (Nerita). This study of a representative of the most geometrically complex calcareous microstructure (also the most widely shared among mollusk shells) suggests a general value to the above described biomineralization mechanism.

\section{Experimental Section}

- Optical microscopy includes observation by transmitted light (natural and crossed-nicol polarization), reflected natural light, UV epi-fluorescence by mercury lamp light filtered by UV $(365 \mathrm{~nm})$ and blue $(435 \mathrm{~nm})$ filters using both Zeiss Standard Universal epi-illumination and a Leica TCS-NT SP inverted microscope.

- Confocal microscopy was carried out in the Electron Microscopy and Mineral Analysis Division in the Mineralogy Department at the Natural History Museum (NHM), London using a LEICA TCS-NT SP microscope. Initial tests were carried out using the microscope's wavelength (lambda) scan function which produces a signal intensity plot for each excitation wavelength over a range of detected wavelengths for each laser excitation wavelength used. These plots were used to optimize choice of the excitation laser, and to determine the detector window settings to use for each channel. The plots also assisted in determining the optimum settings for autofluorescence and for reflection mode, and the two laser excitation wavelengths and detector windows were set to minimize interference.

A $488 \mathrm{~nm}$ argon laser was chosen for excitation of fluorescence with a detector window set for FITC-type emission (515-545 nm). A $633 \mathrm{~nm}$ helium-neon laser was used with a detector window set at $625-641 \mathrm{~nm}$ to detect reflection from the crystalline shell structure at the same spatial position.

- SEM observations were carried out using a Philips XL30 equipped with a secondary electron and a back-scattered electron (BSE) detector. In this latter method, image contrast is due to the difference in BSE ratio which depends on the atomic number of atoms composing the substrate material. Thus, using a $30 \mathrm{kV}$ acceleration voltage and a maximum detector contrast, BSE method provides very readable pictures of the distribution of organic envelopes and calcium carbonate phases. 
- Electron Backscattered Diffraction (EBSD) is an in situ microscopy technique that provides the crystallographic orientation of crystals on highly polished surface of samples. Prior to analysis, samples are coated with $2.5 \mathrm{~nm}$ of carbon and surrounded by silver paint to avoid electron charging. EBSD analyses were performed using a Hikari camera (EDAX) mounted in a FEI Quanta 3D Dual Beam (CAF-University of Alabama, Gadsden, Alabama, USA). The sample was tilted $70^{\circ}$, and the electron beam diffracted by interaction with crystal planes in the sample. The diffracted beam interacts with a phosphor screen producing a series of Kikuchi bands (diffraction patterns) that enable crystal identification and orientation to be determined. Finally, data were analyzed using OIM 5.3 from EDAX-TSL.

- Atomic Force Microscopy (AFM) data were obtained at room temperature and in air using a Digital Instruments (Veeco) Nanoscope III Dimension 3100 instrument housed at the geological laboratory of de University Paris-Sud Orsay. The Digital Instruments probe consists of a cantilever with an integrated silicon nitride tip. Most of the data were acquired using the tapping mode with three types of resulting pictures. "height" pictures, providing a direct imaging of the surface topography, "amplitude" imaging, a derived signal emphasizing the changes in surface slope, and a "phase contrast" imaging mode, in which the signal is formed by the difference between the theoretical position of the tip (based on the vibration frequency) and its actual position as indicated by the reflected laser beam. Depending on variations in physical properties of the observed surface, such as hardness, elasticity, adhesiveness etc., the phase-lag level is modified during the scanning process.

- Micro-XANES mapping (X-ray Absorption Near Edge Structure spectroscopy) Biochemical mapping was carried out at the ID21 beam-line of the European Synchrotron Radiation Facility. The ID21 Scanning X-ray microscope uses Fresnel zone plates as focusing optics to generate a submicron X-ray probe. An energy-dispersive high-purity Ge detector (Princeton, Gamma-Tech) mounted in the horizontal plane perpendicular to the beam collects the fluorescence emission photons. This geometry minimizes the contribution of elastic scattering. An energy range between 2 and $7 \mathrm{keV}$ is available, which gives access to the sulfur Kedge at $2472 \mathrm{eV}$ (sulfur in amino acids) and $2482.5 \mathrm{eV}$ (sulfated sulfur in polysaccharides) [31]. The XANES energy scan around the sulfur K-edge is achieved using a fixed-exit double-crystal Si (111) monochromator located upstream from the microscope, which offers the requested energy resolution. This experiment required the X-ray microscope to be operated under vacuum to avoid the strong absorption of the sulfur emission lines by air.

\section{Conclusions}

1. Structural, chemical and biochemical data converge to suggest that crystallization of biogenic calcium carbonate produced by a cellular epithelium (e.g., mollusk mantles, coral basal ectoderms) occurs in organic gel layers, the thickness of which is in the micrometer range, cyclically secreted by the mineralizing organs.

2. Crystallization is thought to occur as the last step in formation of the growth layer. Simultaneously, two or three different environmental signals are recorded, according to the 
species-specific distribution of the distinct mineralizing areas (multiple and simultaneously active "vital effects").

3. Shaping of the resulting polycyclic calcareous biocrystals is linked to their stepping growth mode. A growth-layer cycle comprises formation of envelopes made of insoluble organic materials acting as spatial limiting factors during the crystallization step of the biomineralization cycle.

4. As a result of this crystallization process, the mineral phases exhibit a specific reticulate pattern built by tightly packed and fused nodular units, the margins of which being marked by an irregular organic rich coating.

5. Through important variations among phyla the layered control of crystallization appear as an essential component of the "common strategy" developed by the living systems for controlling deposition of Ca-carbonates which built their mineralized hard-parts.

\section{References}

1. Bowerbank, J.S. On the structure of the shells of Molluscous and Conchiferous Animals. Trans. Microsc. Soc. London 1844, 1, 123-154.

2. Carpenter, W. On the microscopic structure of shells: Part I. Br. Assoc. Adv. Sci. 1845, 14, 1-24.

3. Carpenter, W. On the microscopic structure of shells: Part II. Br. Assoc. Adv. Sci. 1847, 17, 93-134.

4. Schmidt, W. Die Bausteine des Tierkorpers in Polarisiertem Lichte; Cohen Verlag: Bonn, Germany, 1924.

5. Boggild, O. The shell structure of the Mollusks. Skrifter Naturvidenskabelig Math. Afd. Raeke 9 1930, 9, 231-326.

6. Ogilvie, M. Microscopic and systematic study of the madreporarian types of corals. Phil. Trans. R. Soc. Lond. B 1895, 59, 9-18.

7. Ogilvie, M. Microscopic and systematic study of the madreporarian types of corals. Phil. Trans. R. Soc. Lond. B 1896, 187, 83-345.

8. Furla, P.; Galgani, I.; Durand, I. Sources and mechanisms or inorganic carbon transport for coral calcification and photosynthesis. J. Exp. Biol. 2000, 203, 351-371.

9. Adkins, J.F.; Boyle, E.A.; Curry, W.B.; Lutringer, A. Stable isotopes in deep-sea corals and a new mechanism for "vital effects". Geochim. Cosmochim. Acta 2003, 67, 1129-1143.

10. Petit, H. Recherches sur des séquences d'événements périostracaux lors de l'élaboration de la coquille d'Amblema plicata Conrad, 1834. PhD Thèse. Laboratoire de Zoologie, Université de Bretagne occidentale: Brest, France, 1978.

11. Saleuddin, A.S.M.; Petit, H. The mode of formation and the structure of the periostracum. In The Mollusca; Saleuddin, A.S.M., Wilbur, K.M., Eds.; Academic Press: New York, NY, USA, 1983; volume 4, pp. 199-234.

12. Volkmer, D. Biologically inspired crystallization of calcium carbonate beneath monolayer: A critical overview. In Handbook of Biomineralization; Behrens, P., Baeuerlein, E., Eds.; Wiley: New York, NY, USA, 2007; Volume 2, pp. 65-87.

13. Jacob, D.E.; Soldati, A.L.; Wirth, R.; Huth, J.; Wehrmeister, U.; Hofmeister, W. Nanostructure, composition and mechanisms of Bivalve shell growth. Geochim. Cosmochim. Acta 2008, 72, 5401-5415. 
14. Dove, P. The rise of skeletal biominerals. Elements 2010, 6, 37-42.

15. Tambutté, E.; Tambutté, S.; Segonds, N.; Zoccola, D.; Venn, A.; Erez, J.; Allemand, D. Calcein labelling and electrophysiology: Insight on coral tissue permeability and calcification. Proc. R. Soc. Lond. B 2011, doi:10.1098/rspb.2011.0733.

16. Weiner, S. Mollusk shell formation: Isolation of two organic matrix proteins associated with calcite deposition in the bivalve Mytilus californianus. Biochemistry 1983, 22, 4139-4145.

17. Addadi, L.; Moradian, J.; Shaye, E. A chemical model for the cooperation of sulfates and carboxylates in calcite crystal nucleation: Relevance to biomineralization. Proc. Natl. Acad. Sci. USA 1987, 84, 2732-2736.

18. Kitano, Y.; Hood, D.W. The influence of organic material on polymorphic crystallization of calcium carbonate. Geochim. Cosmochim. Acta 1965, 29, 29-41.

19. De Yoreo, J.J.; Dove, P.M. Shaping crystals with biomolecules. Science 2004, 306, 1301-1302.

20. Lowenstam, H.A.; Weiner, S. On Biomineralization; Oxford University Press: Oxford, UK, 1989.

21. Wilt, E.H.; Kilian, C.E.; Livingston, B.T. Development of calcareous skeletal elements in invertebrates. Differenciation 2003, 71, 237-250.

22. Wilt, E.H.; Ettensohn, C.A. The morphogenesis and biomineralization of the sea urchin larval skeleton. In Handbook of Biomineralization; Behrens, P., Baeuerlein, Eds.; Wiley: New York, NY, USA, 2007; pp. 183-210.

23. Lowenstam, H.A. Minerals formed by organisms. Science 1981, 211, 1126-1131.

24. Veis, A. A window on biomineralization. Science 2005, 307, 1419-1420.

25. Ubukata, T. Nucleation and growth of crystals and formation of cellular pattern of prismatic shell microstructure in bivalve molluscs. Forma 2001, 16, 141-154.

26. Grégoire, C. Sur la structure submicroscopique de la conchyoline associée aux prismes de coquilles de mollusques. Bul. Inst. R. Sci. Nat. Belgique 1961, 37/3, 1-34.

27. Cuif, J.P.; Denis, A.; Gaspard, D. Recherche d'une méthode d'analyse ultrastructurale des tests carbonatés d'Invertébrés. Bul. Soc. Géol. France 1981, 9, 525-534.

28. Cuif, J.P.; Dauphin, Y.; Denis, A.; Raguideau, A. Etude des caractéristiques de la phase minérale dans les structures prismatiques du test de quelques Mollusques. Bull. Mus. Natl. Hist. Nat. 1983, 5, 679-717.

29. Dauphin, Y. Soluble organic matrices of the calcitic prismatic shell layers of two pteriomorphid Bivalves: Pinna nobilis and Pinctada margaritifera. J. Biol. Chem. 2003, 278, 15168-15177.

30. Cuif, J.P.; Dauphin Y.; Sorauf, J.E. Biominerals and Fossils through Time; Cambridge University Press: Cambridge, UK, 2011.

31. Dauphin, Y.; Cuif, J.P.; Doucet, J.; Salomé, M.; Susini, J. In situ mapping of growth lines in the calcitic prismatic layers of mollusc shells using X-ray absorption near-edge structure (XANES) spectroscopy at the sulphur edge. Mar. Biol. 2003, 142, 299-304.

32. Checa, A.G.; Esteban-Delgado, F.J.; Ramirez-Rico, J.; Rodrigez-Navarro, A.B. Crystallographic reorganization of the calcitic prismatic layer of oysters. J. Struct. Biol. 2009, 167, 261-270.

33. Checa, A.G.; Ramirez-Rico, J.; Gonzalez-Segura, A. Nacre and false nacre (foliated aragonite) in extant monoplacophorans (Tryblidiia: Mollusca). Naturwissenschaften 2009, 96, 111-122. 
34. Dauphin, Y.; Brunelle, A.; Cotte, M.; Cuif, J.P.; Farre, B.; Laprévote, O.; Meibom, A.; Salomé, M.; Williams, C.T. A layered structure in the organic envelopes of the prismatic layer of the shell of the pearl oyster Pinctada margaritifera (Mollusca, Bivalvia) Micros. Microanal. 2010, 16, 91-98.

35. Guzmann, N.; Ball, A.D.; Cuif, J.P.; Dauphin, Y.; Ortlieb, L. Subdaily growth patterns and organomineral nanostructure of the growth layers in the calcitic prisms of the shell of Concholepas concholepas Bruguière, 1789 (Gastropoda, Muricidae). Micros.Microanal. 2007, 13, 397-403.

36. Bryan,W.H.; Hill, D. Spherulitic crystallization as a mechanism of skeletal growth in the hexacorals. Proc. R. Soc. Qld. 1941, 52, 9, 78-91.

37. Cuif, J.P.; Lecointre, G.; Perrin, C.; Tillier, A.; Tillier, S. Patterns of septal biomineralization in Scleractinia compared with their $28 \mathrm{~S}$ rRNA phylogeny: A dual approach for a new taxonomic framework. Zool. Scr. 2003, 32, 459-473.

38. Cuif, J.P.; Dauphin, Y. The environment recording unit in coral skeletons: A synthesis of structural and chemical evidences for a biochemically driven, stepping growth process in coral fibers. Biogeosciences 2005, 2, 61-73.

39. Cuif, J.P.; Dauphin, Y. Occurrence of mineralization disturbances in nacreous layers of cultivated pearls produced by Pinctada margaritifera var. cumingi from French Polynesia. Comparison with reported shell alterations. Aquat. Liv. Res. 1996, 9, 187-193.

40. Dauphin, Y.; Ball, A.D.; Cotte, M.; Cuif, J.P.; Meibom, A.; Salomé, M.; Susini, J.; Williams, C.T. Structure and composition of the nacre-prism transition in the shell of Pinctada margaritifera (Mollusca, Bivalvia). Anal. Bioanal. Chem. 2008, 390, 1659-1169.

41. Erben, H.K. Ueber die bildung und das wachstum von perlmutt. Biomineralization 1972, 4, 16-36.

42. Mutvei, H. On the internal structures of the nacreous tablets in molluscan shells. Scan. Elect. Micros. 1979, II, 451-462.

43. Nudelman, F.; Gotliv, B.A.; Addadi, L.; Weiner, S. Mollusk shell formation: Mapping the distribution of organic matrix components underlying a single aragonitic tablet in nacre. J. Struct. Biol. 2006, 153, 176-187.

44. Cuif, J.P.; Dauphin, Y. Microstructural and physico-chemical characterizations of the "centers of calcification" in the septa of some recent Scleractinian corals. Paläont. Zeit. 1998, 72, 257-270.

45. Vandermeulen, J.H.; Watabe, N. Studies on reef corals: I. Skeleton formation by newly settled planula larva of Pocillopora damicornis. Mar. Biol. 1973, 23, 47-57.

46. Cuif, J.P.; Dauphin,Y.; Doucet, J.; Salomé, M.; Susini J. XANES mapping of organic sulfate in three scleractinian coral skeletons. Geochim. Cosmochim. Acta 2003, 67, 75-83.

47. Adkins, J.F.; Boyle, E.A.; Curry, W.B.; Lutringer, A. Stable isotopes in deep-sea corals and a new mechanism for "vital effects". Geochim. Cosmochim. Acta 2003, 67, 1129-1143.

48. Blamart, D.; Cuif, J.P.; Juillet-Leclerc, A.; Rollion-Bard, C. O-stable isotopes distribution in deep-sea corals from SIMS measurements. In Proceedings of the 27th General Assembly of the European Geophysical Society, Nice, France, 21-26 April 2002; volume 4, EGS02-A-01713.

49. Rollion-Bard, C.; Blamart, D.; Cuif, J.P. Juillet-leclerc microanalysis of $\mathrm{C}$ and $\mathrm{O}$ isotopes of azooxanthellate and zooxanthellate corals by ion microprobe. Coral Reefs 2003, 22, 405-415. 
50. Meibom, A.; Cuif, J.P.; Hillion, F.; Constantz, B.; Juillet-Leclerc, A.; Dauphin, Y.; Watanabe, T.; Dubar, R.B. Distribution of magnesium in coral skeleton. Geoph. Res. Lett. 2004, 31, L23306:1-L23306:4.

51. Clode, P.L.; Marshall, A.T. Low temperature FESEM of the calcifying interface of a scleractinian coral. Tissue Cell 2002 34, 187-198.

52. Crenshaw, M.A. Mechanisms of shell formation and dissolution. In Skeletal Growth of Aquatic Organisms; Rhoads, D.C., Lutz, R.A., Eds.; Plenum Press: New York, NY, USA, 1980; pp. 115-132.

53. Wilbur, K.M. Shell Formation and Regeneration. In Physiology of Mollusca; Wilbur, K.M., Yonge, C.M., Eds.; Academic Press: New York, NY, USA and London UK, 1964; Volume 1, pp. 243-282.

54. Kessel, E Über die Schale von Viviparus viviparus L. and Viviparus fasciatus Müll. Ein Beiträge zum Strukturproblem der Gastropodenschale. Z. morphol. Ökol Tiere 1933, 27, 129-198.

55. Johnston, I.S. Aspects of the structure of a skeletal organic matrix and the process of skeletogenesis in the reef-coral Pocillopora damicornis. In 3rd International Coral Reef Symposium; Pennsylvania State University: University Park, PA, USA, 1977; pp. 447-453.

56. Johnston, I.S. The ultrastructure of skeletogenesis in hermatypic corals. Int. Rev. Cytol. 1980, 67, $171-214$.

57. Friedbacher, G.; Hansma, P.K.; Ramli, E.; Stucky, G.D. Imaging powders with the atomic force microscope: From biominerals to commercial materials. Science 1991, 253, 1261-1262.

58. Crenshaw, M. The soluble matrix from Mercenaria mercenaria shell. Biomineralization 1972, 6 , 6-11.

59. Baronnet, A.; Cuif, J.P.; Dauphin, Y.; Farre, B.; Nouet, J. Crystallization of biogenic Ca-carbonate within organo-mineral micro-domains. Structure of the calcite prisms of the pelecypod Pinctada margaritifera (Mollusca) at the submicron to nanometer ranges. Miner. Mag. 2008, 72, 617-626.

60. Bourne, G.C. Studies on the structure and formation of the calcareous skeleton of the Anthozoa. Quart. J. Microsc. Sci. 1899, 41, 499-547.

61. Goreau, T. Histochemistry of mucopolysaccharide-like substances and alkaline phosphatase in Madreporaria. Nature 1956, 4518, 1029-1030.

62. Lécuyer, C.; O’Neil, J.R. Composition isotopique (H, O) de l'eau en inclusion dans les carbonates biogéniques. Bull. Soc. Géol. Fr. 1994, 165, 573-581.

63. Cuif, J.P.; Dauphin, Y.; Berthet, P.; Jegoudez, Y. Associated water and organic compounds in coral skeletons: Quantitative thermogravimetry coupled to infrared absorption spectrometry. Geochem. Geophys. Geosyst. 2004, 5, Q11011:1-Q11011:9.

64. Beniash, E.; Aizenberg, J.; Addadi, L; Weiner, S. Amorphous calcium carbonate transforms into calcite during sea urchin larval spicule growth. Proc. R. Soc. Lond. B 1997, 264, 461-465.

65. Pokroy, B.; Quintana, J.P.; Caspie,N.; Berner, A.; Zolotoyabko, O.E. Anisotropic lattice distorsions in biogenic aragonite. Nature 2004, 3, 900-902.

66. Bevelander, G.; Nakahara, H. Compartment and envelope formation in the process of biological mineralization. In The Mechanisms of Biomineralization in Animals and Plants; Omori, M., Watabe, N., Eds.; Tokai University Press: Kanagawa, Japan, 1980; pp. 19-27.

67. Wada, K. Crystal growth of molluscan shells. Bull. Natl. Pearl Res. Lab. 1961, 36, 703-828. 
68. Cölfen, H. Non classical crystallization. In Biomineralization from Paleontology to Material Sciences; Arias, J.L., Fernandez M.S., Eds.; Editorial Universitaria Santiago: Santiago, Chile; 2007; pp. 515-526.

69. Cölfen, H.; Antonietti M. Mesocrystals and Nonclassical Crystallization; Wiley: New York, NY, USA, 2008.

70. Williams, A.; Carlson, S.J.; Howard, C.; Brunton, C.; Holmer, L.E.; Popov, L. A supra-ordinal classification of the Brachiopoda. Phil. Trans. R. Soc. Lond. B 1996, 351, 1171-1193.

71. Cusack, M.; Dauphin, Y.; Chung, P.; Perez-Huerta, A.; Cuif, J.P. Multiscale structure of calcite fibres of the shell of the brachiopod Terebratulina retusa. J. Struct. Biol. 2008, 164, 96-100.

72. Smout, A.H. Reclassification of the Rotaliidae (Foraminifera). J. Wash. Acad. Sci. 1955, 45, 201-210.

73. Moureaux, C.; Pérez-Huerta, A.; Compère, P.; Zhu, W.; Leloup, T.; Cusack, M.; Dubois, P. Structure, composition and mechanical relations to function in sea urchin spine. J. Struct. Biol. 2010, 170, 41-49.

74. Zhang, F.; Cai, W.; Zhu, J.; Sun, Z.; Zhang J. In-situ raman spectral mapping study on the microscale fibers in blue coral (Heliopora coerulea) skeletons. Anal. Chem. 2011, 83, 7870-7875.

75. Nouet, J.; Baronnet, A.; Howard, L. Crystallization in organo-mineral micro-domains in the crossed-lamellar layer of Nerita undata (Gastropoda, Neritopsina). Micron 2011, 43, 456-462.

(C) 2012 by the authors; licensee MDPI, Basel, Switzerland. This article is an open access article distributed under the terms and conditions of the Creative Commons Attribution license (http://creativecommons.org/licenses/by/3.0/). 